\title{
Net effect of the QBO in a chemistry climate model
}

\author{
H. J. Punge ${ }^{1,2}$ and M. A. Giorgetta ${ }^{1}$ \\ ${ }^{1}$ Max Planck Institute for Meteorology, Bundesstr. 53, 20146 Hamburg, Germany \\ ${ }^{2}$ IMPRS on Earth System Modelling, Bundesstr. 53, 20146 Hamburg, Germany
}

Received: 13 May 2008 - Published in Atmos. Chem. Phys. Discuss.: 19 June 2008

Revised: 27 August 2008 - Accepted: 20 September 2008 - Published: 13 November 2008

\begin{abstract}
The quasi-biennial oscillation (QBO) of zonal wind is a prominent mode of variability in the tropical stratosphere. It affects not only the meridional circulation and temperature over a wide latitude range but also the transport and chemistry of trace gases such as ozone. Compared to a QBO less circulation, the long-term climatological means of these quantities are also different. These climatological net effects of the QBO can be studied in general circulation models that extend into the middle atmosphere and have a chemistry and transport component, so-called Chemistry Climate Models (CCMs). In this work we show that the CCM MAECHAM4CHEM can reproduce the observed QBO variations in temperature and ozone mole fractions when nudged towards observed winds. In particular, it is shown that the QBO signal in transport of nitrogen oxides $\mathrm{NO}_{\mathrm{x}}$ plays an important role in reproducing the observed ozone $\mathrm{QBO}$, which features a phase reversal slightly below the level of maximum of the ozone mole fraction in the tropics. We then compare two 20year experiments with the MAECHAM4-CHEM model that differ by including or not including the QBO. The mean wind fields differ between the two model runs, especially during summer and fall seasons in both hemispheres. The differences in the wind field lead to differences in the meridional circulation, by the same mechanism that causes the QBO's secondary meridional circulation, and thereby affect mean temperatures and the mean transport of tracers. In the tropics, the net effect on ozone is mostly due to net differences in upwelling and, higher up, the associated temperature change. We show that a net surplus of up to $15 \%$ in $\mathrm{NO}_{\mathrm{x}}$ in the tropics above $10 \mathrm{hPa}$ in the experiment that includes the QBO does not lead to significantly different volume mixing ratios of ozone. We also note a slight increase in the southern vortex strength as well as earlier vortex formation in northern
\end{abstract}

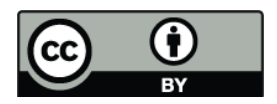

Correspondence to: H. J. Punge (heinzjuergen.punge@zmaw.de) winter. Polar temperatures differ accordingly. Differences in the strength of the Brewer-Dobson circulation and in further trace gas concentrations are analysed. Our findings underline the importance of a representation of the QBO in CCMs.

\section{Introduction}

The representation of the stratosphere in present-day general circulation models (GCMs) such as those used for the IPCC AR4, is usually simple. Specific processes driving stratospheric dynamics, i.e. the dynamics of waves and the transport and chemistry of trace gases can not be included in these models for their high computational cost. But the interest in projections for stratospheric ozone concentrations and stratospheric climate impacts has led to the development of the so called chemistry-climate models (CCMs) that cover these processes to different degrees. Recently, Eyring et al. (2006) presented an intercomparison of such models.

The effects of the quasi-biennial oscillation (QBO) of equatorial zonal winds (see the review of Baldwin et al., 2001) are a prominent example for the complex interaction of dynamics, trace gas transport and trace gas chemistry in the stratosphere. QBO variations were found in satellite observations for many trace gases including ozone, methane and water vapor (Randel and Wu, 1998; O'Sullivan and Dunkerton, 1997; Randel et al., 1998; Dunkerton, 2001; Patra et al., 2003; Randel et al., 2004). More recently, Schoeberl et al. (2008) presented a comprehensive study of QBO signals in multiple trace gases from HALOE and Aura MLS observations. There is growing interest in studying the QBO in chemistry climate models. Firstly, CCMs provide a unique way to study these effects in a consistent manner. Secondly, the representation of the QBO and its effects is an interesting test case for CCMs. Still, like most GCMs, many CCMs fail to represent the QBO entirely, which may lead to significant deficiencies in the results from these models, especially in

Published by Copernicus Publications on behalf of the European Geosciences Union. 
the representation of the stratospheric circulation and composition, which can have effects on the troposphere via dynamic or radiative links.

Several studies validated or showed QBO signals in CCMs, e.g. see the work of Steinbrecht et al. (2006) who compared ozone concentrations and temperatures in CCMs to satellite observations and reanalysis. Chipperfield et al. (1994), Bruhwiler and Hamilton (1999) and Tian et al. (2006) discussed the QBO signal in ozone and nitrogen oxides and their chemical connection. Previous analyses have mostly focused on the actual variation of the circulation, trace gas concentrations and chemical processes.

In contrast, the goal of this work is to analyze the average net effect of introducing a realistic QBO into the circulation on the long term. This is done using the chemistry climate model MAECHAM4-CHEM. The nudging technique of Giorgetta and Bengtsson (1999) offers the opportunity to include a realistic QBO, based on observations at Singapore, in the MAECHAM4-CHEM model, which otherwise does not have a QBO, unlike the ECHAM5 simulations of (Giorgetta et al., 2006) and (Lelieveld et al., 2007), where the QBO is simulated due to model improvements and a higher vertical resolution. The variations induced by the QBO, e.g. in tropical ozone, can be compared directly to observations, due to the assimilation of observed QBO winds. The comparison of two otherwise largely identical experiments that are described in Sect. 2, of which one is nudged to the observed QBO for 20 years and the other one is not, reveals the net effect of the QBO. Here, we are not primarily interested in the difference between selected states of the QBO and the noQBO state, but in the climatological difference on a decadal time scale. The length of the experiments was chosen accordingly to average over a reasonable number of QBO cycles and many different phase combinations of annual and QBO cycles to give a realistic view of the long term effect.

For many considerations on longer time scales, the net effects of the QBO may be far more important than the QBO variations themselves. Specifically, such effects are not limited to the QBO region for a given quantity, and may exceed the actual QBO range in other places, as will be discussed below.

The QBO's net effect will be shown for a number of variables that are directly affected by the QBO and its secondary meridional circulation. For the dynamic aspect, we chose zonal wind and temperature. They show pronounced QBO imprints that are well understood (Plumb and Bell, 1982; Huesmann and Hitchman, 2001; Baldwin et al., 2001). Regarding trace gases, we restrict ourselves to the discussion of ozone. Net effects on selected other trace species, i.e. methane, $\mathrm{NO}_{\mathrm{x}}$ and water vapor, as well as the net differences in the stream function, are included in an appendix.
The results of this study are particularly interesting in the light of the recent development of general circulation models that produce a QBO. Currently, the Japanese models at CCSR/NIES (Takahashi, 1996) and MRI (Shibata and Deushi, 2005), the SKYHI model of GFDL (Hamilton and Hsieh, 2002), the models UMETRAC and UMSLIMCAT of the UK Met Office (Austin, 2002) and ULeeds (Tian and Chipperfield, 2005) and the models MAECHAM5 (Giorgetta et al., 2006) and HAMMONIA (Schmidt et al., 2006), when used with a high vertical resolution grid, have a representation of the QBO. Our approach can show the improvement of the general circulation and tracer representation to be expected in such models compared to conventional non-QBO models. Some of the aforementioned models may also offer the possibility to remove the QBO by modifications to the model, e.g. by reducing the vertical resolution. In that case, however, these modifications may themselves have an impact on the circulation that is entangled with the QBO's effect. The main advantage of using a nudged model is that the nudging presents a very minor modification to the model simulation and thus the net impact of the QBO can be addressed directly and consistently.

Section 2 describes the CCM runs used for this study and the methods of analysis used. The QBO in the model is evaluated by comparing the anomalies to the ERA- 40 reanalysis and results from satellite observations. Section 3 deals specifically with the models representation of the QBO in ozone. Section 4 shows the net effect of the QBO in wind and temperature in comparison to the amplitude of the QBO while Sect. 5 discusses the net effect on ozone. Implications are discussed in Sect. 6. The Appendix presents a synopsis of annual and seasonal net effects of the QBO in the mass stream function, methane, humidity and nitrogen oxides.

\section{Model and comparison to observations}

The MAECHAM4-CHEM CCM consists of the middle atmosphere version of the ECHAM4 climate model (Manzini and McFarlane, 1998; Roeckner et al., 1996) and the interactively coupled chemistry model CHEM (Steil et al., 1998, 2003; Manzini et al., 2003). The circulation is computed by the spectral transform method at T30 truncation, associated to a Gaussian longitude-latitude grid with a spacing of 3.75 degrees, and has 39 vertical layers between the surface and $0.01 \mathrm{hPa}$. Transport and physical and chemical processes are computed in grid point space. The chemistry scheme includes the most important species and reactions of troposphere and stratosphere. Radiative feedbacks of the computed $\mathrm{O}_{3}, \mathrm{H}_{2} \mathrm{O}$ and $\mathrm{CH}_{4}$ are processed in the climate model.

The two experiments described here run from 1980-2000. Sea surface temperatures are from HadISST1 (Rayner et al., 2003) and greenhouse gases and halogens are as used for the WMO/UNEP assessment 2002 (WMO, 2003). The first experiment (noQBO) is free-running and does not reproduce 
the quasi-biennial oscillation. The second experiment (QBO) is in contrast forced to have a QBO equivalent to observations using the nudging technique: tropical stratospheric winds are relaxed linearly to the observed winds from the Singapore radiosondes, which is close to the equatorial maximum of the QBO. The applied forcing is zonally uniform with a Gaussian profile with the full width of half maximum around the Equator ranging from 20 degrees at $70 \mathrm{hPa}$ to 30 degrees at $10 \mathrm{hPa}$. Observations from seven altitude levels between 70 and $10 \mathrm{hPa}$ are used until 1986, when measurements on 14 levels between 90 and $10 \mathrm{hPa}$ became available. Above $10 \mathrm{hPa}$, the QBO jets are extended vertically, assuming a steady downward propagation of $2 \mathrm{~km} /$ month between 10 and $3 \mathrm{hPa}$.

The time constant used for the nudging is 7 days. This time scale is a compromise between a time scale as long as possible to avoid impacts on fast wind fluctuations that are not part of the QBO time evolution and a time scale short enough to obtain a realistic QBO structure. Tests showed that a timescale of about 7 to 10 days is reasonable.

Clearly, using zonal wind nudging towards observations from only one equatorial site, Singapore in our case, is a potential source of artifacts as hemispheric and zonal asymmetries are neglected. Hemispheric asymmetries can be expected e.g. due to the asymmetry in the wave forcing of the QBO, but there is few observational evidence that these are important. There exist stationary zonal asymmetries in the lowermost equatorial stratosphere at the Equator. However, above $70 \mathrm{hPa}$, where the nudging sets in, these are small, and it is reasonable for the purpose of this study to assume a zonal symmetry of the QBO jets, which is also supported by earlier studies (e.g., Naujokat, 1986).

Furthermore, in the nudged experiment, solar activity is parameterized using radiation flux data by Lean et al. (1997) and the aerosol forcing caused by volcanic eruptions is included by prescribing precalculated net heating rates of Kirchner et al. (1999) and the surface area densities of Jackman et al. (1996) for the chemistry module. These two observational forcings were not included in the simulation without QBO nudging. They introduce additional sources of interannual variability to the QBO run, mainly the 11-year solar cycle and the eruptions of El Chichon in April 1982 and Pinatubo in June 1991. However, for the quantities of interest here, their impact should be either small or well understood, as e.g. the stratospheric temperature and water vapor response to tropical volcanic eruptions. 2-year time sections following the eruptions of El Chichon and Mt. Pinatubo are excluded from the comparison for this reason. Tourpali et al. (2003) report an ozone variation of $2-3 \%$ in the upper stratosphere due to the solar cycle, but on average over the entire period of the experiment these variations will nearly cancel, and the net effect related to the 11-year solar cycle will be far lower than this number. Thus, comparing the two experiments is still very effective for the identification of the QBO's net impact on the stratosphere. The nudged exper-

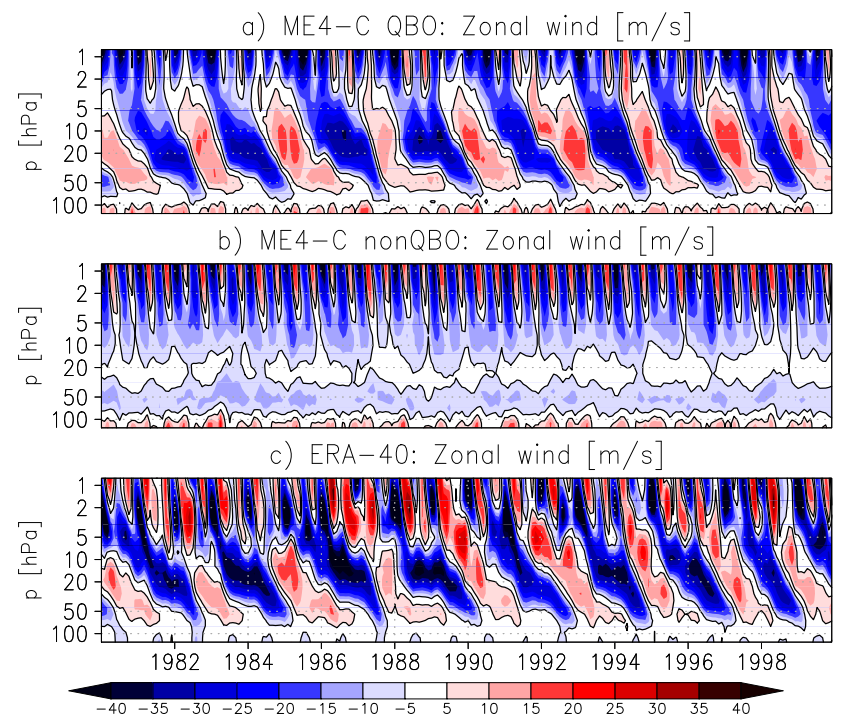

Fig. 1. Zonal mean zonal wind $[\mathrm{m} / \mathrm{s}]$ in the equatorial stratosphere, mean between $5^{\circ} \mathrm{S}$ and $5^{\circ} \mathrm{N}$, (a) MAECHAM4-CHEM (ME4-C) nudged QBO experiment; (b) MAECHAM4-CHEM free running experiment; (c) ERA-40 reanalysis. Black contours are drawn at $\pm 5 \mathrm{~m} / \mathrm{s}$.

iment described here has previously been evaluated within the SPARC CCMVal activity (Eyring et al., 2006) on the validation of chemistry-climate models.

Figure 1 displays the time series of zonal mean zonal wind at the Equator for the period of the experiments. Figure 1a shows the zonal mean zonal wind for the nudged QBO experiment, Fig. $1 \mathrm{~b}$ for the non-QBO experiment, and Fig. 1c for the ERA-40 reanalysis (Uppala et al., 2004). Notice the close agreement of the nudged experiment and the reanalysis in the structure of the QBO jets below $10 \mathrm{hPa}$ where direct wind observations exist. The easterlies are slightly stronger in the reanalysis than in the model. This may be because the additional data sources assimilated in ERA-40 differ from the Singapore winds. Besides the QBO, the model also reproduces the semi-annual oscillation (SAO) of zonal wind in the upper stratosphere. It is however slightly weaker than in the reanalysis.

In the non-QBO experiment, the winds are almost constant easterly by $5-10 \mathrm{~m} / \mathrm{s}$ throughout the lower and middle stratosphere. The SAO is more pronounced than in the QBO experiment.

Compared to the QBO experiment, the SAO also extends further down in the experiment without QBO. In particular, the SAO westerlies are suppressed in the QBO experiment when there are QBO westerlies in the middle stratosphere and the westerly wave forcing from the troposphere is mostly absorbed at the QBO jets and does not reach the SAO region. The SAO easterlies during the solstitial seasons are mostly due to the mean flow from the summer towards the 


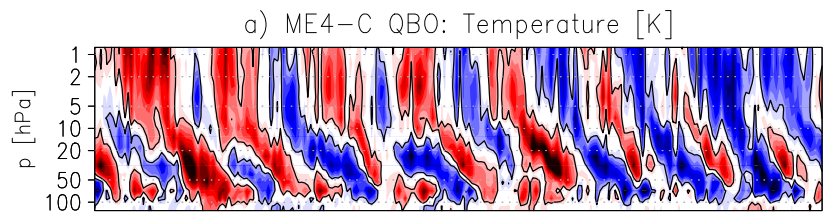

b) ME4-C nonQBO: Temperature $[\mathrm{K}]$

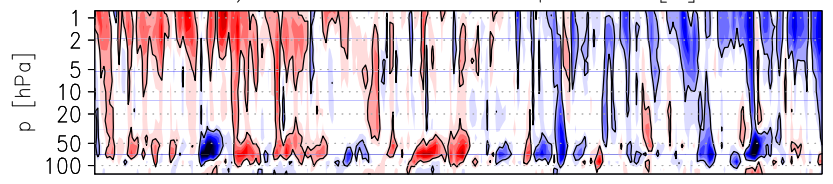

c) ERA-40: Temperature $[\mathrm{K}]$

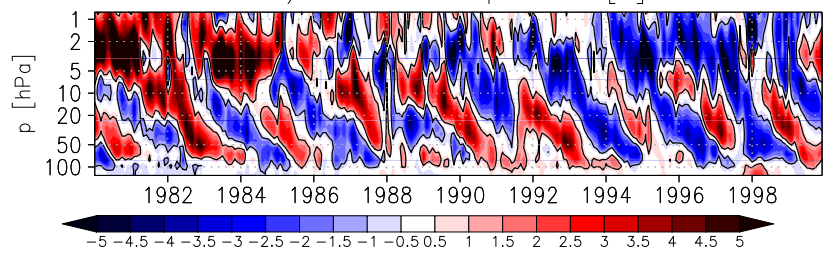

Fig. 2. As Fig. 1, but for the zonal mean temperature anomalies $[\mathrm{K}]$ (monthly climatology subtracted). Black contours are drawn at $\pm 1 \mathrm{~K}$.

winter hemisphere in the mesosphere during these seasons and therefore not affected as severely by this effect. Also see the discussion on this issue in Giorgetta et al. (2006), who compared two experiments that have a QBO or no QBO due to different vertical resolutions. They noted similar differences in the SAO due to the presence of the QBO using a model that generates the QBO spontaneously.

In ERA-40, the annual asymmetry between the two cycles of the SAO is more pronounced than in the model experiments, and is generally more variable. This is a consequence of the too low resolved wave driving in the CCM, one reason why it does not produce a QBO spontaneously. The weakening of the SAO phases above equal QBO phases can also be recognized. Note, however, that there is some uncertainty to the ERA-40 data above $10 \mathrm{hPa}$, because there is rather few data available at these levels (Uppala et al., 2004; Punge and Giorgetta, 2007).

We conclude from this figure that the representation of the zonal wind in the QBO model experiment is quite realistic and the non-QBO experiment is typical for a climate model without QBO. The underestimation of the SAO in both simulations, mostly in the equinox seasons, may affect the residual meridional circulation in the stratopause region. However, we do not expect this issue to bias our analysis of the net effect heavily. Thus, the pair of experiments, for which the zonal mean zonal wind is shown in Fig. 1, is still suitable for our comparison in this respect.

Figure 2 shows the temperature anomalies for the two model experiments and the ERA-40 reanalysis. Thermal wind balance explains the temperature QBO signal which is phase shifted with respect to zonal wind by about $1 / 4$ cycle (e.g. Baldwin et al., 2001). The representation of the temperature QBO is realistic in the nudged model run. In comparison to ERA-40, some differences are noticed in the upper stratosphere. One reason is in the differences in the representation of the SAO mentioned above. But some of these differences may again be due to deficiencies in the ERA-40 (Punge and Giorgetta, 2007). For an analysis of the temperature QBO in the nudged version of MAECHAM4-CHEM in comparison to observations we refer to Steinbrecht et al. (2006). They evaluated a model experiment that is almost identical to the QBO experiment in this study, except for its duration of 40 years.

The non-QBO experiment shows little interannual variability. As in the QBO experiment and in the reanalysis, there is a long term cooling trend in the upper stratosphere due to the combined effects of reduced ozone due to $\mathrm{CFC}$ emissions, which leads to a reduced amount of short wave radiative heating, and the increase in greenhouse gases, especially of $\mathrm{CO}_{2}$, which leads to increased long wave cooling in the middle atmosphere (e.g., Akmaev, 2006). There are cold anomalies in the lower stratosphere in 1983 and 1998 following the El Nino events in these years. Their presence in the noQBO simulation, but neither in the QBO simulation nor in the ERA-40 data, suggests that the QBO is important for studies on the impact of El Nino in the tropical stratosphere.

The warm and cold anomalies of the temperature QBO signal correspond to phases of weaker and stronger upwelling in the tropics, respectively. Together with the variation of the latitudinal velocities, this forms the QBO's secondary meridional circulation (SMC) that modulates the Brewer-Dobson circulation (BDC), which leads to the QBO imprint on the mass stream function (Plumb and Bell, 1982). It is clear that the secondary meridional circulation impacts any trace gases and substances with vertical or horizontal gradients and sufficiently long life time in the tropical stratosphere (Trepte and Hitchman, 1992; Chipperfield and Gray, 1992; Randel and Wu, 1998; Randel et al., 1998; Patra et al., 2003; Tian et al., 2006; Schoeberl et al., 2008).

Ozone is the most prominent example for a tracer that varies with the QBO. The modulation of the ozone column in our model was investigated by Steinbrecht et al. (2006). In this article, the vertical distribution of ozone is of particular interest.

Figure 3 shows the 6-year climatological mean vertical profile for the period 1992-1998 of ozone in the two model experiments, in comparison to HALOE satellite observations. The modelled profile is close to that of HALOE at and above the maximum at $10 \mathrm{hPa}$ in both simulations. In the lower stratosphere, the model overestimates mixing ratios by up to 1 ppmv. The model run with QBO is slightly closer to the HALOE data than the noQBO run at most levels. This net difference will be discussed in detail in Sect. 5. However also note in this context that recent radiosonde observations 
suggest that HALOE results underestimate ozone concentrations in the lower stratosphere (Witte et al., 2008).

A number of different effects of the QBO impact the vertical profile of ozone via both transport and chemistry, making modelling a difficult task. In Fig. 4, the equatorial $\left(2^{\circ} \mathrm{S}\right.$ to $\left.2^{\circ} \mathrm{N}\right)$ ozone anomalies over the period $1991-$ 1999 are given for available HALOE measurements and the two MAECHAM4-CHEM model runs. The QBO signal in $\mathrm{HALOE} \mathrm{O}_{3}$ data given here was obtained by interpolation to a monthly time series. A similar evaluation was applied by Cordero et al. (1997). To illustrate the phase delay with respect to the zonal wind, contours of modelled and observed wind are overplotted. Observed wind is taken from the same Singapore radiosonde data set as used for nudging the model.

We find good agreement between the nudged model and the HALOE data. The downward propagation of the anomalies, following the QBO jets, is well represented, including the phase shift at $15 \mathrm{hPa}$. The magnitude of the modelled anomaly is somewhat lower than in the HALOE record, at about $0.5 \mathrm{ppmv}$ both at 8 and $30 \mathrm{hPa}$ compared to about 0.8 ppmv. In the QBO model run, we also find an imprint of the eruption of Mt. Pinatubo during the two years after June 1991 that is weaker in the satellite observations. During this period, volume mixing ratios are decreased below $20 \mathrm{hPa}$, and increased above, which may relate to the water vapor anomalies due to the eruption.

In the non-nudged model there is interannual variability probably related to the lower stratospheric temperature modulation by ENSO in this run. Anomalies are in opposite phase in the lower and upper stratosphere, with a phase reversal at $15 \mathrm{hPa}$ as in the $\mathrm{QBO}$ run, but vertical propagation is instantaneous. There is a negative trend in the upper stratosphere that is related to increase in chlorine species.

A detailed discussion of the QBO impact on the chemistry and transport of ozone in the model is instructive for the later evaluation of the net effect and follows in the next section.

Figures 1 to 4 show the nudging technique is appropriate to introduce a realistic QBO into a model and that the representation of the QBO effects on temperature and ozone is in good agreement with observations.

\section{Chemistry and transport impact on ozone by the QBO}

A vertically resolved record of ozone anomalies due to the QBO in SAGE satellite observations was first shown by Zawodny and McCormick (1991). They argued that the equatorial QBO signal was due to the advection of ozone by the SMC in the lower stratosphere and by modulation of the ozone chemistry above, with anomalies of nitrogen oxides, mainly $\mathrm{NO}$ and $\mathrm{NO}_{2}$, playing a major role in the latter. It is clear that the chemical lifetime of $\mathrm{O}_{3}$ decreases significantly with altitude (e.g. Brasseur et al., 1999), thereby limiting the direct impact of advection at higher levels. In the

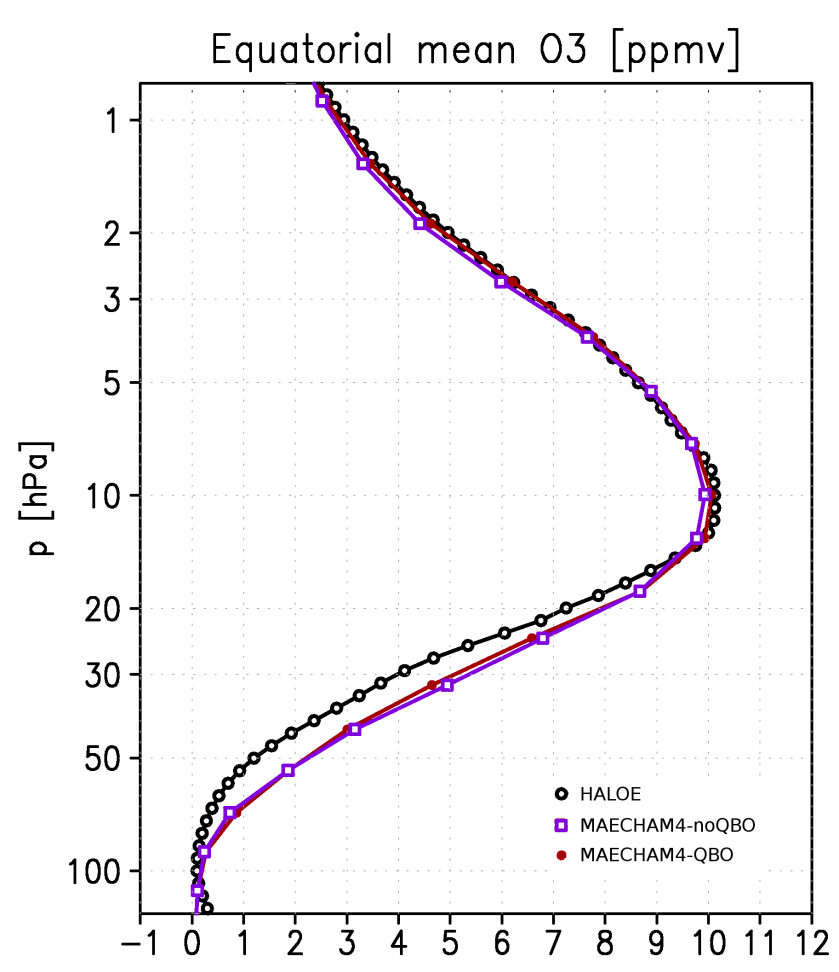

Fig. 3. Profile of zonal mean ozone mixing ratios [ppmv] in the equatorial stratosphere, averaged over six years of HALOE observations (black) and the respective time interval in the MAECHAM4CHEM model with (red) and without (violet) nudged QBO.

upper stratosphere, the modulation of temperatures due to the modulation of upwelling by the SMC is assumed to alter the equilibrium state of ozone chemistry and cause variations in phase with the upwelling.

The respective roles of ozone transport and chemistry in the formation of the QBO signal have however been debated. Hasebe (1994) presented anomalies of the ozone QBO in the tropical mean volume mixing ratio in SAGE data with an amplitude of about 0.5 and $1 \mathrm{ppmv}$, or about $10 \%$, in the lower and upper branch of the signal, respectively. Randel et al. (1998) updated and extended the analysis of the SAGE record, and another update was given in Logan et al. (2003). Logan et al. (2003) also presented the ozone QBO signal derived from sonde measurements at Nairobi and San Christobal. They report a signal of $15-20 \%$ in the lower branch near the Equator. This is somewhat stronger than in the SAGE data, which suggest an amplitude of 10-15\% if only measurements close to the Equator $\left(2^{\circ} \mathrm{S}-2^{\circ} \mathrm{N}\right)$ are taken into account. The QBO signal in HALOE ozone data given in Fig. 4 was also analyzed by Cordero et al. (1997), who report an amplitude of $0.8 \mathrm{ppmv}$ in both branches for the latitude range $4^{\circ} \mathrm{S}$ to $4^{\circ} \mathrm{N}$, similar to the equatorial SAGE evaluations. Dunkerton (2001) and Schoeberl et al. (2008) also evaluate HALOE data and found an amplitude of about 

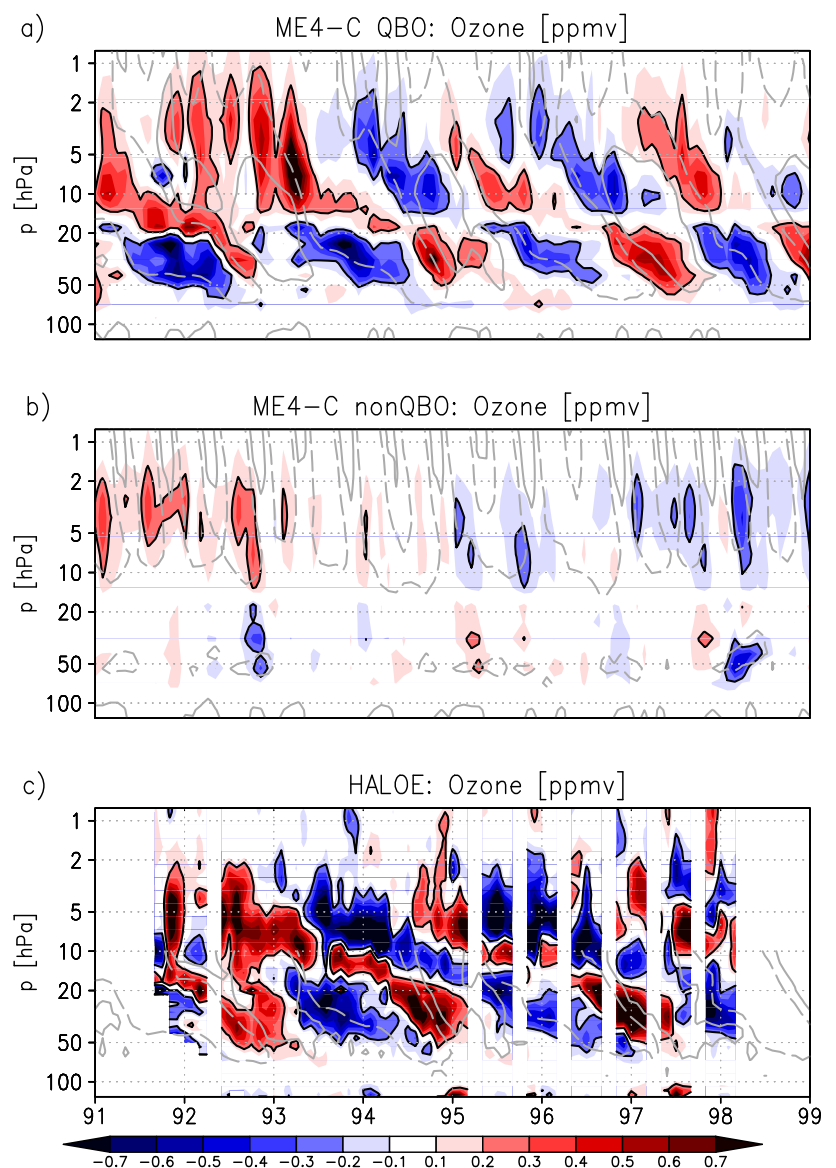

Fig. 4. Shading gives the anomalies of the zonal mean ozone volume mixing ratio [ppmv] in the tropical stratosphere in (a) the MAECHAM4-CHEM nudged QBO experiment; (b) the MAECHAM4-CHEM free running experiment, (c) HALOE observations. Black contours are drawn at \pm 0.2 ppmv. Grey contours show zonal mean zonal wind in the model experiments (a) and (b) and as observed at Singapore (c). Solid and dashed contours are drawn at $\pm 10 \mathrm{~m} / \mathrm{s}$ to mark westerly and easterly QBO phases, respectively.

0.4 ppmv in the tropics. Recently, Witte et al. (2008) found good agreement between HALOE records and sonde observations from the SHADOZ network in the lower branch of the QBO anomaly within $10^{\circ}$ of the Equator, with an amplitude of about 1 ppmv.

In all records that have coverage in this altitude range, the signal is split at about $15 \mathrm{hPa}$ in the tropics, where time series show a phase shift of nearly $180^{\circ}$. This phase reversal occurs below the maximum volume mixing ratio at $10 \mathrm{hPa}$, where it would be expected if advection alone were responsible for the signal. A contribution of $\mathrm{NO}_{\mathrm{x}}$ to the QBO signal at these altitudes, as suggested by the studies of Chipperfield and Gray (1992) could in principle explain the shift in altitude of the phase reversal. Recently, Butchart et al.

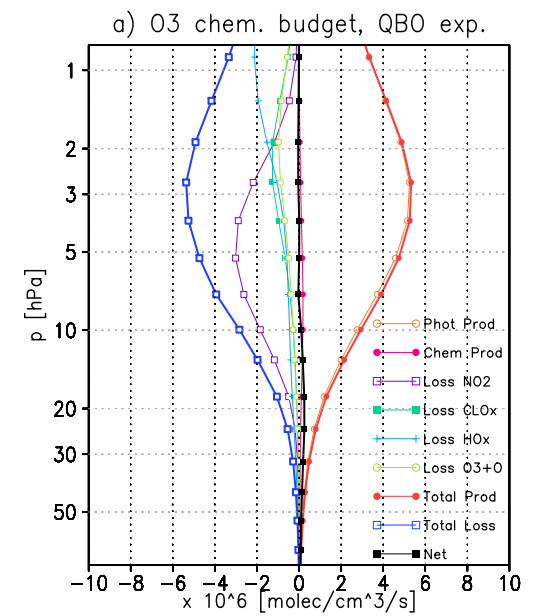

b) 03 budget anomaly, Sep 95

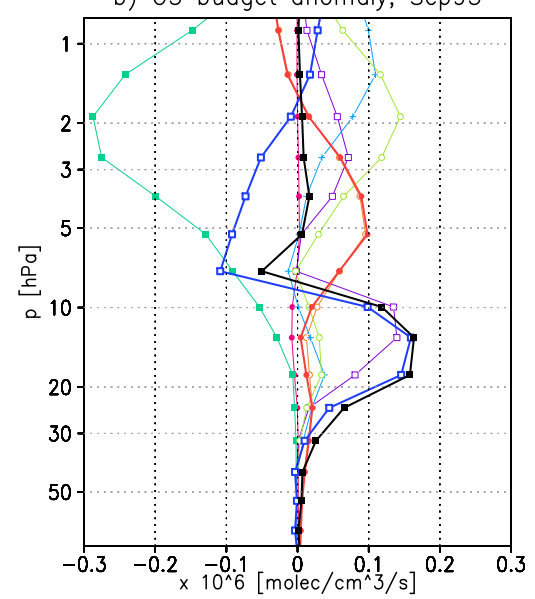

c) 03 budget anomaly, Sep 96

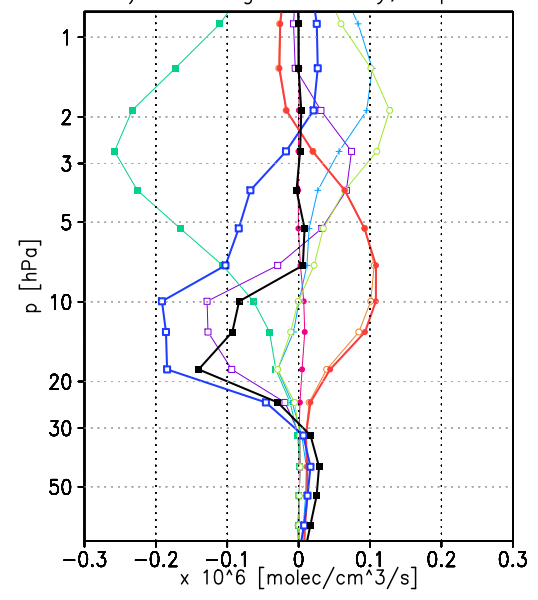

Fig. 5. Contributions to ozone chemical production and loss in the MAECHAM4-CHEM model run with nudged QBO $\left[10^{6} \mathrm{molec} / \mathrm{cm}^{3} / \mathrm{s}\right]$. (a) 20-year mean contributions to chemical production and loss. Net chemical production and net advective gain are also shown. (b) Deviation from the 20-year climatological monthly mean in September 1995, when winds are easterly at $10 \mathrm{hPa}$ (easterly shear at $20 \mathrm{hPa}$ ). (c) Deviation from the 20-year climatological monthly mean in September 1996, when winds are westerly at $10 \mathrm{hPa}$ (westerly shear at $20 \mathrm{hPa}$ ). 
(2003) reproduced a near realistic QBO signal in ozone using a chemistry-climate model that generated a QBO internally but did not include variations in $\mathrm{NO}_{\mathrm{x}}$. However, the phase reversal occurs near $10 \mathrm{hPa}$, close to the maximum of $\mathrm{O}_{3}$ in their model.

Bruhwiler and Hamilton (1999) showed in their model, which had a nudged QBO of fixed period and did not include chlorine chemistry, that the QBO anomaly of net chemical production, mainly by $\mathrm{NO}_{\mathrm{x}}$ anomalies, largely compensates the anomaly by transport above $30 \mathrm{hPa}$, and can be dominant above $15 \mathrm{hPa}$. Their model produces an ozone phase shift near $13 \mathrm{hPa}$, and the magnitude $0.3 \mathrm{ppmv}$ in both upper and lower branch, which appears to be a low estimate.

Tian et al. (2006) used their CCM with internally generated QBO to produce a realistic QBO signal in ozone. The magnitude of the upper branch QBO signal of about $6 \%$ agrees well with their analysis of the SAGE data, while the lower branch of the signal appears slightly underestimated.

The advantage of the MAECHAM4-CHEM model in the version with QBO nudging presented here over previous model studies is that the modelled QBO exactly follows the observed QBO, and hence the modelled QBO in ozone can be compared directly to the observed profile. The good match of the modelled and observed patterns of the signal suggests that, despite the too low amplitude, the relevant processes are represented well in the model.

To distinguish the relative importance of transport and chemical processes for the modelled ozone QBO, it is instructive to separate the ozone gain and loss terms associated with these. The long term averages of these over the course of the QBO experiment are given in Fig. 5a. While chemical production and loss terms were taken directly from the model, the total transport contribution was obtained by summing up advection and eddy transport terms from a transformed Eulerian mean (TEM) analysis of the 6-hourly model output.

Production is mainly due to photolysis of oxygen (orange line), with a minor contribution from the reactions of $\mathrm{HO}_{2}$ and $\mathrm{CH}_{3} \mathrm{O}_{2}$ with $\mathrm{NO}$ (magenta). The above mentioned catalytic loss of ozone by nitrogen oxides (violet), for which $\mathrm{NO}_{2}+\mathrm{O}^{3} \mathrm{P} \rightarrow \mathrm{NO}_{3}+\mathrm{O}_{2}$ is the rate limiting reaction, dominates on the loss side between 20 and $3 \mathrm{hPa}$. Other significant contributions come from the reactions with chlorine $\left(\mathrm{ClO}_{\mathrm{x}}\right.$, aqua) and hydrogen oxides $\left(\mathrm{HO}_{\mathrm{x}}\right.$, light blue $)$ and the recombination $\mathrm{O}_{3}+\mathrm{O}^{3} \mathrm{P} \rightarrow 2 \mathrm{O}_{2}$ (light green).

It is clear from Fig. 5a that chemical production and loss terms cancel to a large degree, especially at higher altitudes. Deviations from the climatological monthly mean are given for two opposite phases of the QBO in Fig. 5b and c. The vertical zonal wind shear is easterly at $20 \mathrm{hPa}$ in September 1995 and westerly one year later, which corresponds to increased and reduced upwelling in these years due to the SMC. In the region between 7 and $25 \mathrm{hPa}$ we find an anomaly in the $\mathrm{NO}_{\mathrm{x}}$ loss rates, which amounts to about $10 \%$ at $13 \mathrm{hPa}$. It can be explained by the model's $\mathrm{NO}_{2}$ anomalies, which are

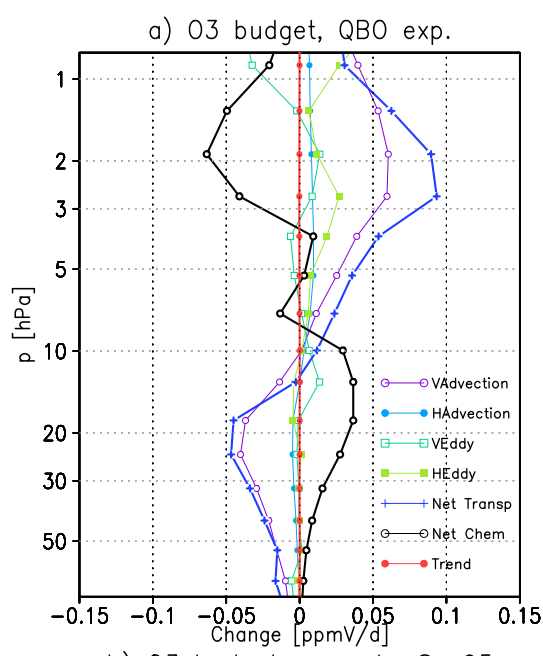

b) 03 budget anomaly, Sep 95

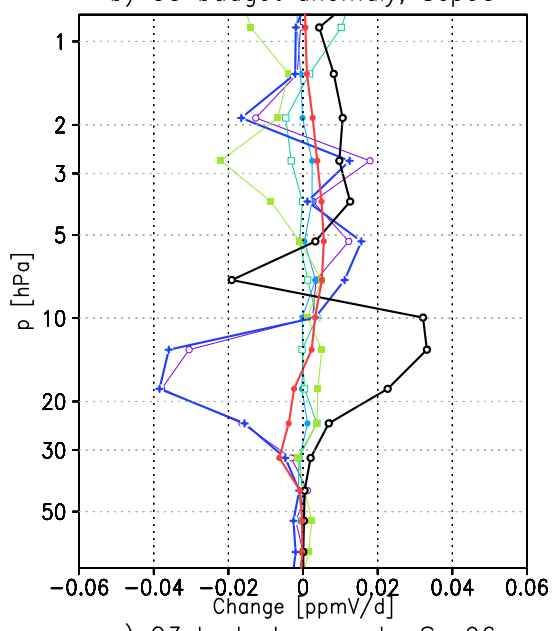

c) 03 budget anomaly, Sep 96

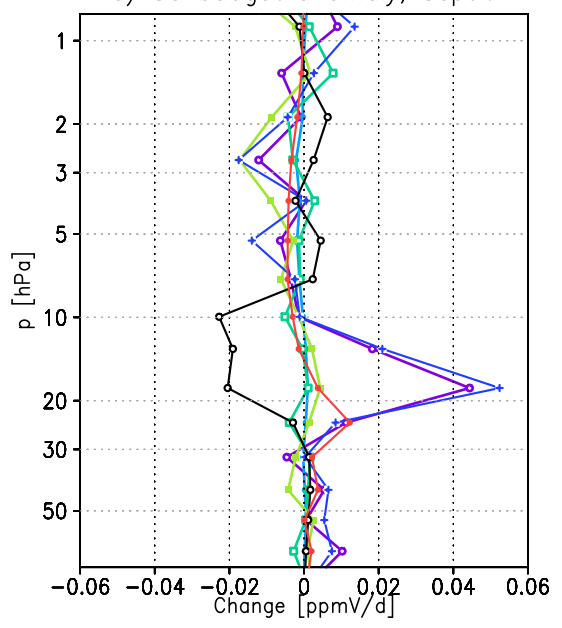

Fig. 6. Contributions of transport and chemistry to the total ozone budget and trend in the nudged MAECHAM4-CHEM model run [ppmv/d]. (a) 20-year mean. (b) Deviation from the 20-year climatological monthly mean in September 1995, when winds are easterly at $5 \mathrm{hPa}$ (easterly shear at $20 \mathrm{hPa}$ ). (c) Deviation from the 20year climatological monthly mean in September 1996, when winds are westerly at $5 \mathrm{hPa}$ (westerly shear at $20 \mathrm{hPa}$ ). 

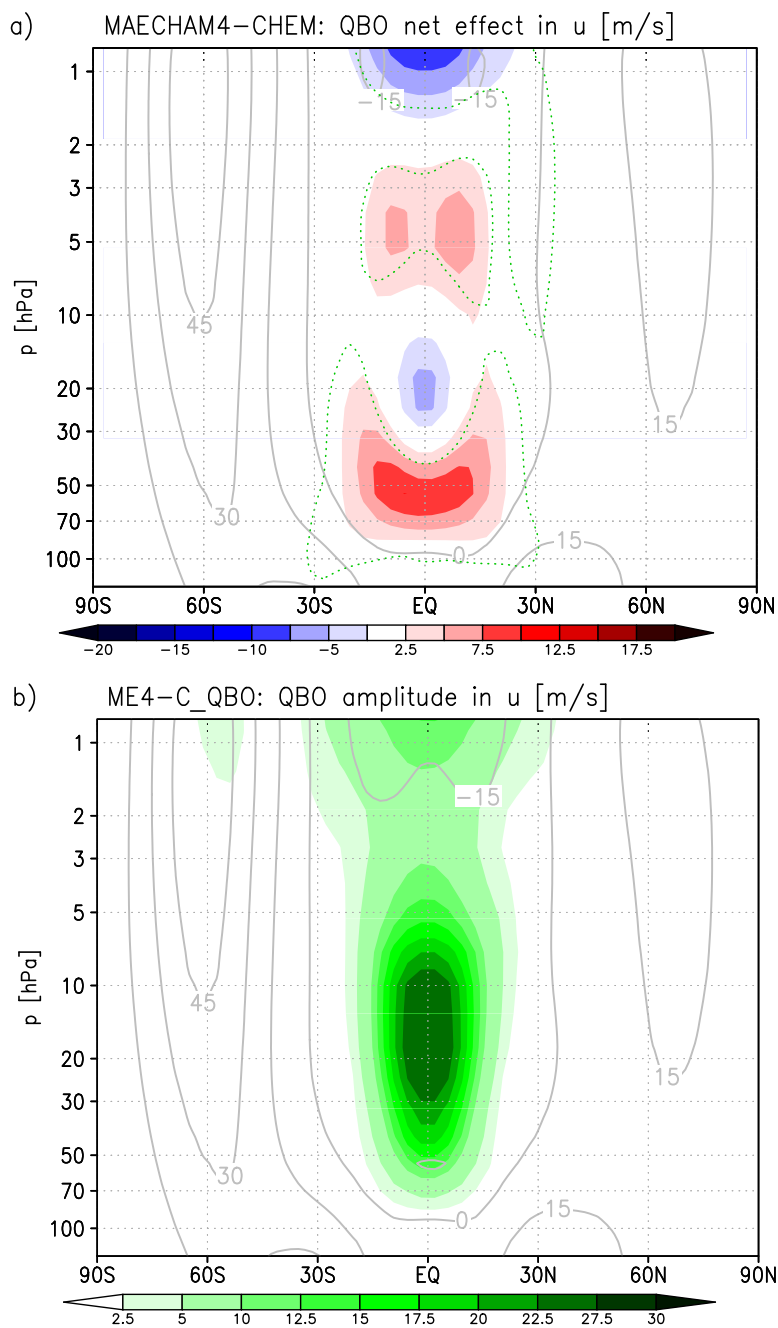

Fig. 7. (a) Shades give the net effect of the QBO on zonal mean zonal wind $[\mathrm{m} / \mathrm{s}]$, obtained by subtracting the climatological annual and zonal mean in the noQBO experiment from the one in the QBO experiment. The solid grey contours show the annual climatological mean zonal wind in the noQBO experiment. Dotted green contours surround the areas where the net effect is significant on the $95 \%$ confidence level. (b) QBO amplitude in the zonal wind $[\mathrm{m} / \mathrm{s}]$ in the QBO experiment, zonal mean. Solid grey contours show the climatological annual mean zonal wind in the QBO experiment.

in opposite phase to the upwelling of the QBO and amount to about $1 \mathrm{ppbv}$ or $10 \%$ at $10 \mathrm{hPa}$, in agreement with Randel and $\mathrm{Wu}(1998)$.

In the region of maximum easterly (westerly) shear, at $17 \mathrm{hPa}$, there is also a decrease (increase) in the loss rates via the $\mathrm{HO}_{\mathrm{x}}$ and $\mathrm{O}+\mathrm{O}_{3}$ reactions, which can be related to the lower (higher) local ozone concentrations in September 1995 (1996). Interestingly, the higher losses in the westerly shear are cancelled to some extent by increased photolytic production between 5 and $15 \mathrm{hPa}$, but this adjustment is smaller in the easterly shear.

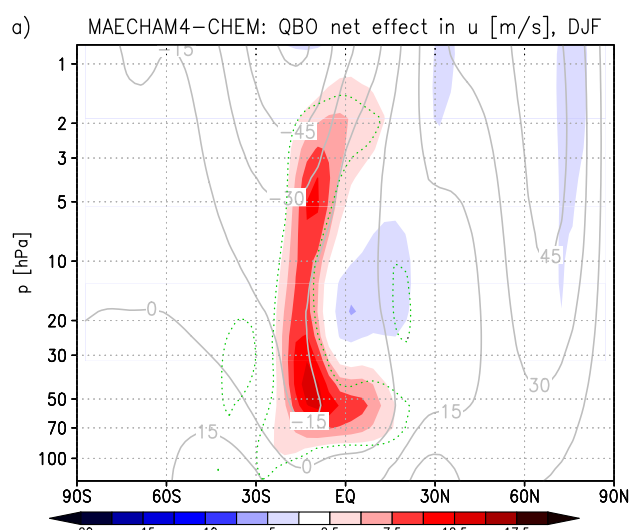

b) MAECHAM4-CHEM: QBO net effect in $\mathrm{u}^{-12}[\mathrm{~m} / \mathrm{s}]$, MAM
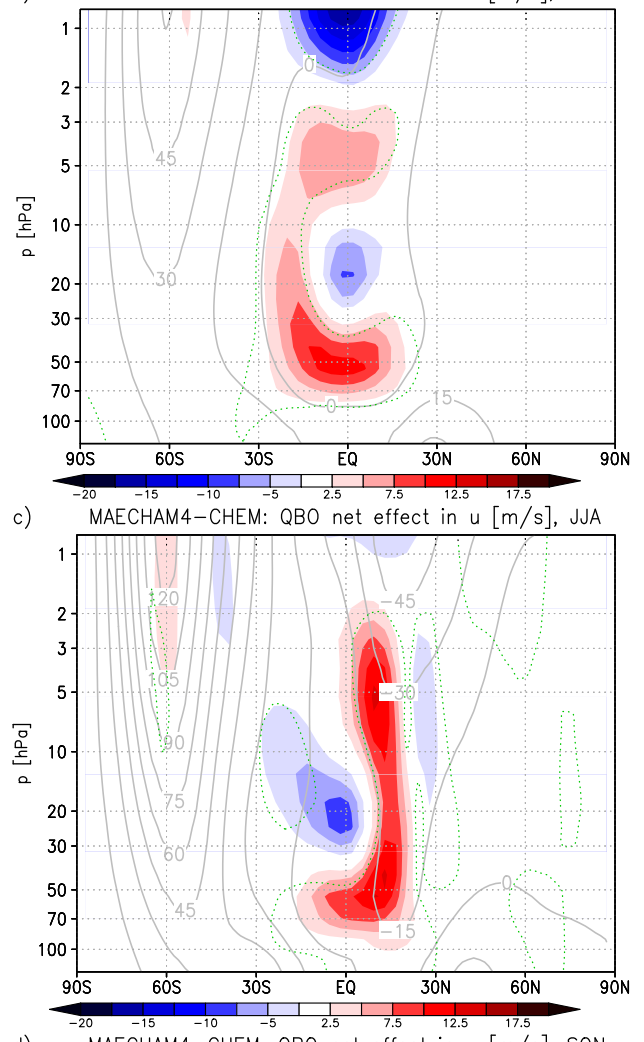

d) MAECHAM4-CHEM: QBO net effect in $u[\mathrm{~m} / \mathrm{s}]$, SON

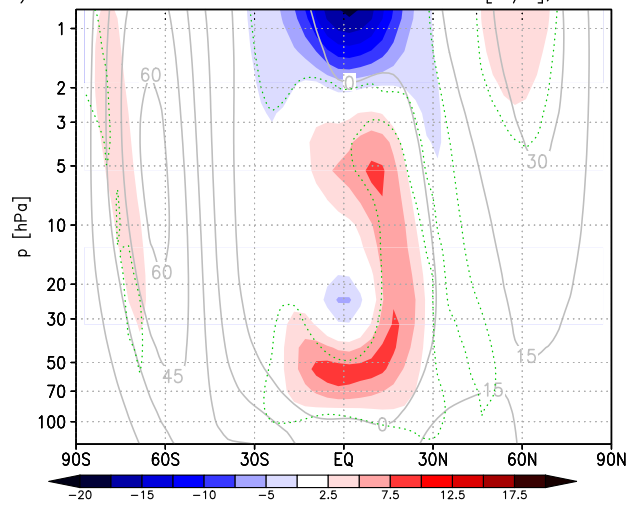

Fig. 8. As Fig. 7a, but for seasons: (a) DJF; (b) MAM; (c) JJA; (d) SON. 
a) MAECHAM4-CHEM: QBO net effect in T [K]

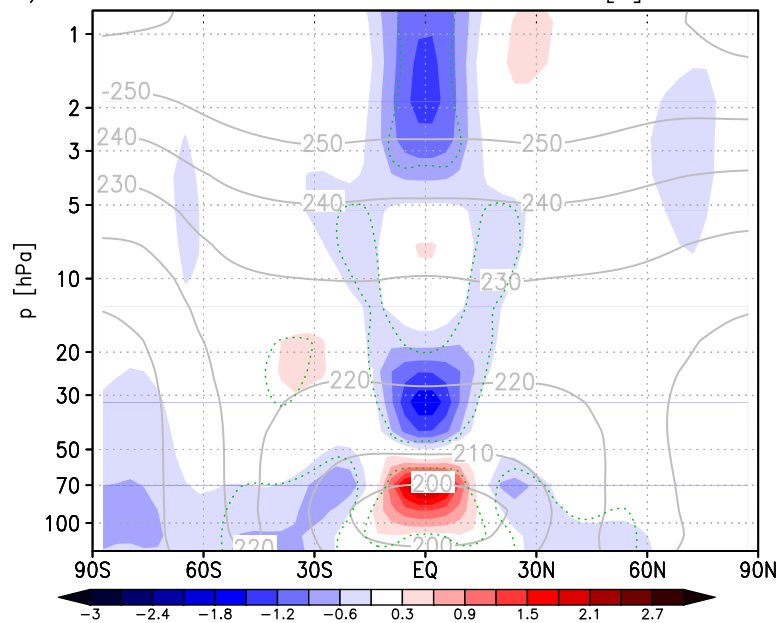

b) ME4-C_QBO: QBO amplitude in T [K]

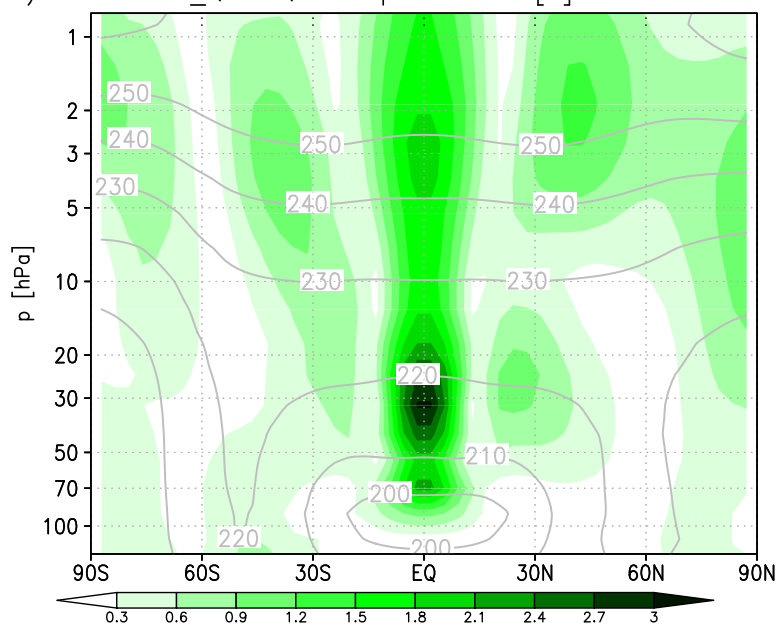

Fig. 9. (a) Shades give the net effect of the QBO on temperature $[\mathrm{K}]$, obtained by subtracting the climatological annual and zonal mean in the noQBO experiment from the one in the QBO experiment. The solid grey contours show the climatological annual mean temperature in the noQBO experiment. Dotted green contours delimit the areas where the net effect is significant on the $95 \%$ confidence level. (b) QBO amplitude in temperature [K] in the QBO experiment, zonal mean. Solid grey contours show the climatological annual and zonal mean temperature in this experiment.

Fig. 6a shows the respective contributions of chemistry and transport to the ozone budget at the Equator, now in $\mathrm{ppmv} / \mathrm{d}$, which is the more instructive unit to study transport. In the long term mean, transport, due to the tropical upwelling, causes loss in the lower stratosphere that is mostly balanced by chemical production. Above the ozone maximum, this relation is reversed, as the ozone vertical gradient is. There is also a significant contribution from eddy transport at higher levels, as suggested by Bruhwiler and Hamilton (1999). The chemical and transport terms do however not cancel entirely. Apparently diffusion, which is not included

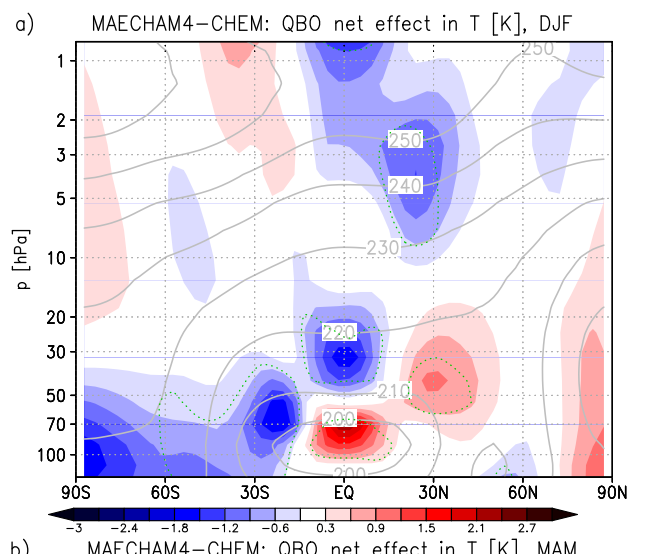

b)

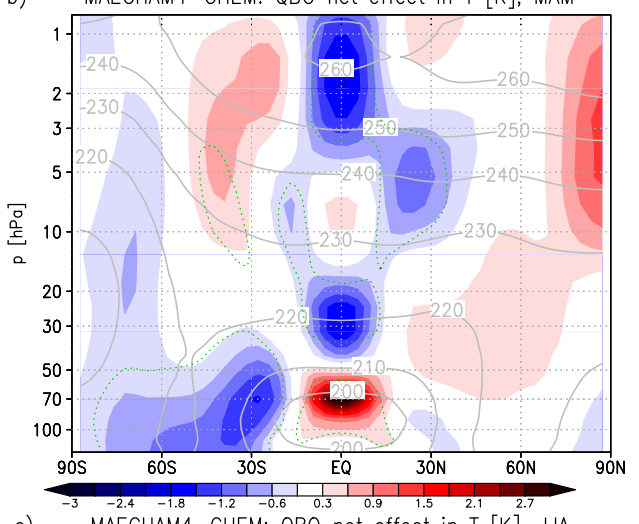

c) MAECHAM4-CHEM: QBO net effect in T [K], JJA

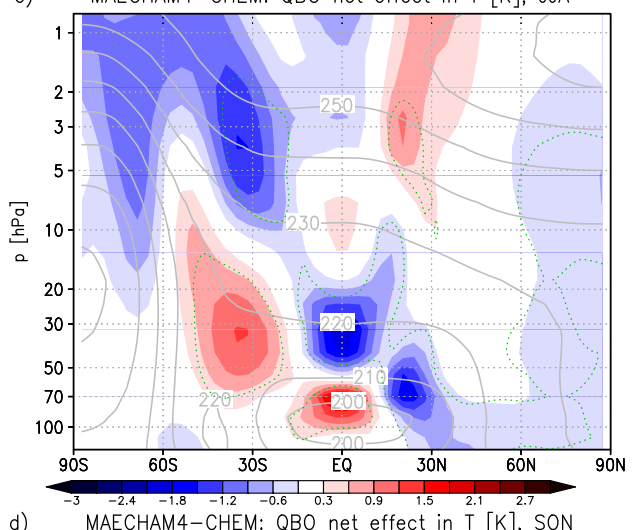

d)

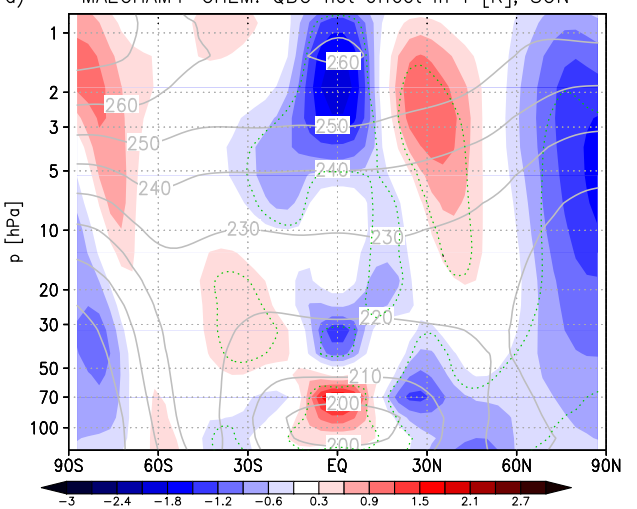

Fig. 10. As Fig. 9a, but for seasons: (a) DJF; (b) MAM; (c) JJA; (d) SON. 
a) 03 chem. budget ano., QBO-noQBO

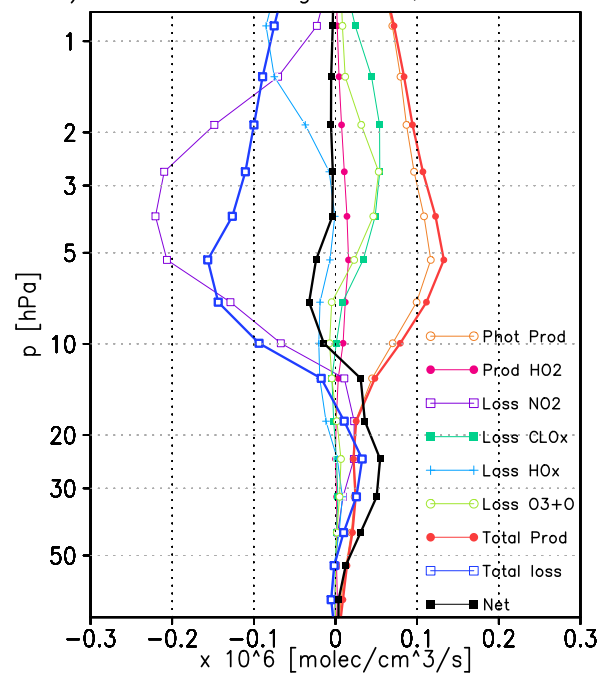

b) 03 budget, QBO - noQBO exp.

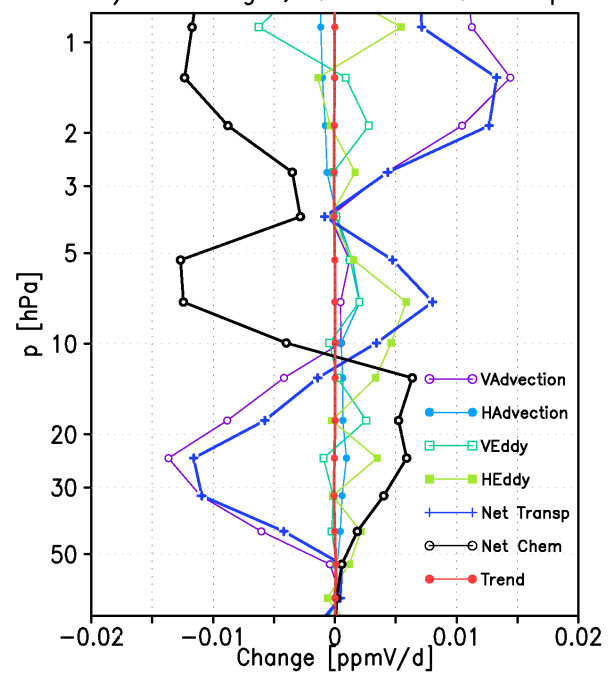

Fig. 11. (a) Net difference in the 20-year mean contributions to ozone chemical production and loss between the MAECHAM4CHEM model runs with and without nudged QBO at the Equator, zonal mean $\left[10^{6} \mathrm{molec} / \mathrm{cm}^{3} / \mathrm{s}\right]$. (b) Net difference in the contributions of transport and chemistry to the total ozone budget and in the ozone trend for the QBO and noQBO experiments, equatorial zonal mean.

in the advective terms given in Fig. 6, plays a role as well, and acts to transport ozone away from the level of maximum mixing ratio. The numerical diffusion in the model has not been diagnosed separately, but it appears reasonable to assume that it balances the net chemical and advective transport contributions in Fig. 6 a.

The sum of the chemical QBO anomalies (Fig. $6 \mathrm{~b}$ and c) is lower than the advective one below the $13 \mathrm{hPa}$ level. As noted above, there is considerable positive chemical net pro-
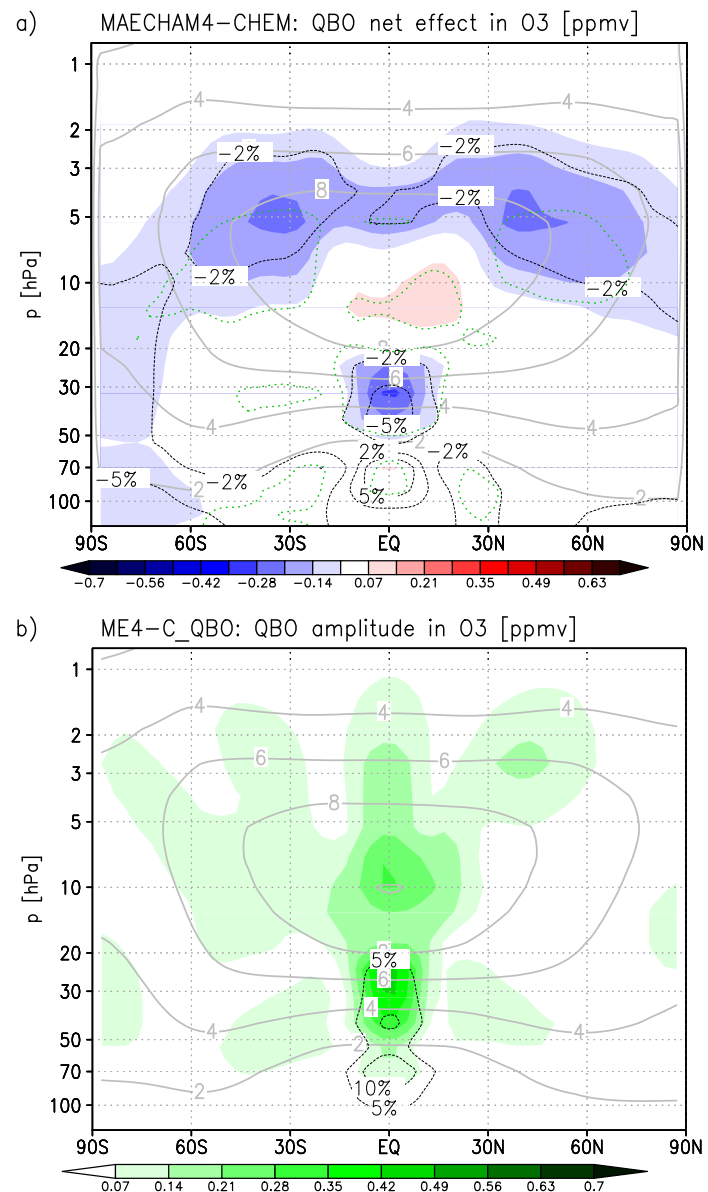

Fig. 12. (a) Shades give the net effect of the QBO on ozone, obtained by subtracting the climatological annual and zonal mean volume mixing ratio [ppmv] in the noQBO experiment from the one in the QBO experiment. Solid grey contours show the climatological annual mean mixing ratio in the noQBO experiment, and solid black contours the relative difference between the two experiments in percent. Dotted green contours delimit the areas where the net effect is significant on the 95\% confidence level. (b) QBO amplitude in the mole fraction of ozone [ppmv] for the QBO experiment, zonal mean. Solid grey contours show the climatological annual mean of the mole fraction in this experiment.

duction (loss) at $10 \mathrm{hPa}$ in the easterly (westerly) phase in September 1995 (1996), while the advective anomaly is zero, for there is no ozone gradient at this level. Still, diffusion will act to lower this anomaly and distribute it to the neighboring levels. For this reason, the total anomaly zeroes below the $12 \mathrm{hPa}$ level, at about $15 \mathrm{hPa}$.

Consequently, the ozone trend anomaly, that is, the difference between the following October and the September, minus the climatological mean of that difference, which produces the QBO anomalies in the mixing ratios, is reversed at $15 \mathrm{hPa}$. At the levels above $10 \mathrm{hPa}$, transport and chemistry 
a) MAECHAM4-CHEM: QBO net effect in 03 [ppmv], DJF

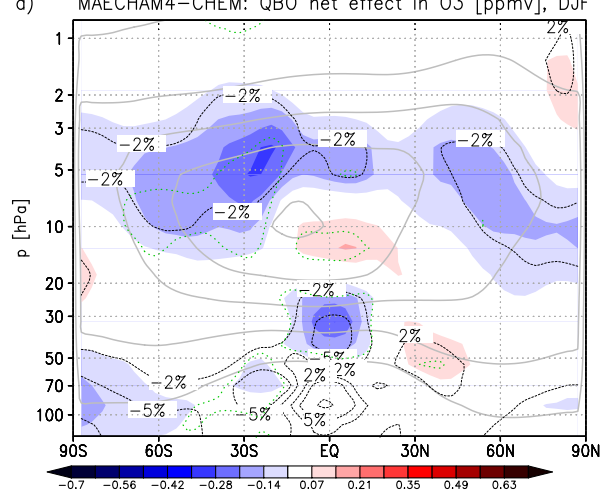

b) MAECHAM4-CHEM: QBO net effect in 03 [ppmv], MAM

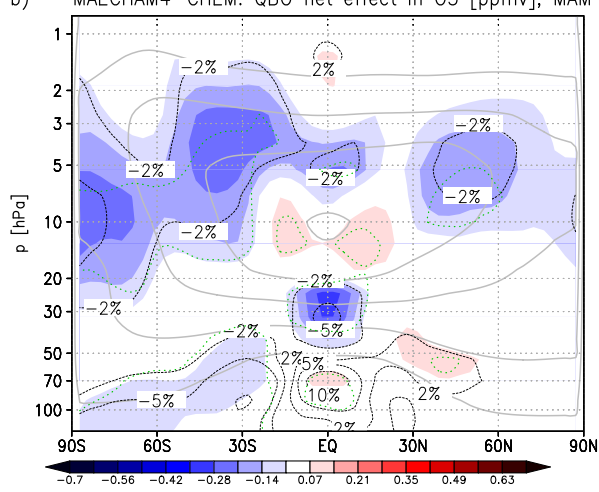

c) MAECHAM4-CHEM: QBO net effect in 03 [ppmv], JJA

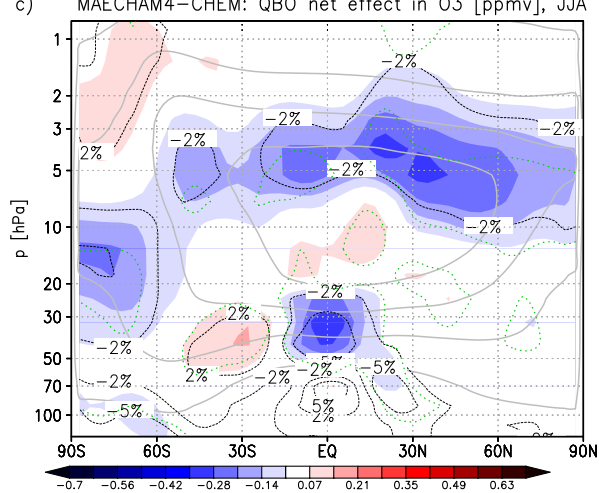

d) MAECHAM4-CHEM: QBO net effect in 03 [ppmv], SON

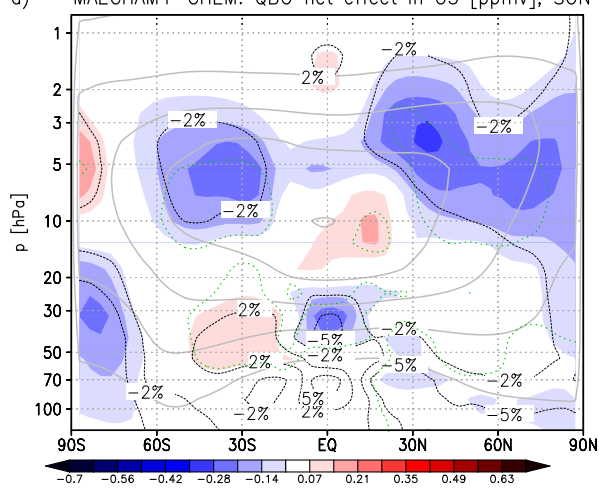

Fig. 13. As Fig. 12a, but for seasons: (a) DJF; (b) MAM; (c) JJA; (d) $\mathrm{SON}$.

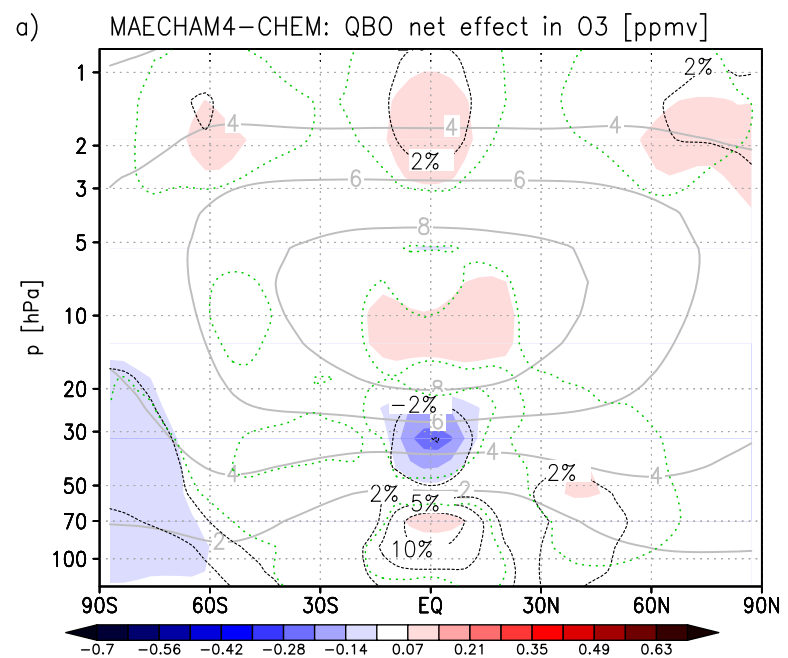

Fig. 14. As Fig.12a, but for a second pair of experiments running from 2000-2019.

contributions should be in phase. But in the chosen example, the wind shear is reduced at these levels and the QBO is in the easterly (westerly) state at $5 \mathrm{hPa}$. As can be seen in Fig. 4, the ozone anomaly is zero there.

This section shows that both chemistry and transport anomalies are important for the formation of the QBO anomalies in ozone at the Equator. Both are primarily due to the anomalies of upwelling that are part of the QBO's secondary circulation. The direct effect by advection of ozone is combined with an indirect one caused by the advection of nitrogen oxides to form the characteristic pattern of anomalies. Both are approximately in phase above $15 \mathrm{hPa}$. However, both observations and model results suggest that the phase shift at $15 \mathrm{hPa}$ is by slightly more than $180^{\circ}$. One should keep in mind that ozone chemistry takes about 1 month at this altitude range to reach its steady state. That will cause the chemical contribution to the signal to be lagged, as it is observed in both model and satellite record.

We also like to stress that while the ozone production anomaly is small compared to the single production and loss terms, it is still much larger than the observed rate of change in ozone in the middle stratosphere, as is the advective contribution. Hence the ozone anomaly is the residual of large contributions and quite sensitive to the circulation.

In the model, diffusion is making a considerable contribution to create the anomaly. As noted before, it is likely overestimated in the model. It will act to dampen the anomalies and explain the too low amplitude of the ozone QBO in the model. Also, an increased vertical resolution should benefit the simulation of the signal, as the advective and the chemical contributions change greatly with altitude. 


\section{Net effect of the QBO on the circulation}

In this section net effects of the QBO are analyzed in zonal wind, temperature and mass stream function. Climatologies are computed for the three quantities based on the long term simulations, which average over the effects of several QBO east and west phases. As explained above, two year periods after the eruptions of El Chichon and Mt. Pinatubo are spared from the analysis to avoid false detection due to the volcano impacts. Furthermore, the year 1999 is spared from the analysis to obtain an integer number of QBO cycles, six in this case. For comparison, the magnitude of the respective QBO variations in the model will be shown, computed using the method of Baldwin and Gray (2005).

First, we analyse the QBO's net effect in zonal wind. It is shown in Fig. 7a. On average, winds are more westerly in the QBO experiment than in the non-QBO experiment both in the lower stratosphere around $50 \mathrm{hPa}$ and in the upper stratosphere around $5 \mathrm{hPa}$. This is mostly because the non-QBO simulation produces easterly winds in the tropics. But in the QBO simulation the asymmetry in the strength and the duration of easterly and westerly phases as in the Singapore radiosonde record is reproduced, and thus the 20-year climatological annual mean zonal wind in the tropical stratosphere of this experiment is different from zero. The easterly QBO jet is strong in the middle stratosphere between 10 and $40 \mathrm{hPa}$ so that in the long term mean, winds are more easterly than in the non-QBO experiment at the Equator. Winds are also more easterly in the uppermost stratosphere at around $1 \mathrm{hPa}$. This is due to the interaction of the QBO and the $\mathrm{SAO}$, which is also reflected in a secondary maximum of the QBO amplitude in Fig. 7b and the different strengths of the SAO in Fig. 1a and b. Different absorption of tropical waves in the different wind conditions of the two model experiments is the main explanation for this effect. In summary, we have a four layer structure for the QBO's net effect on zonal wind which extends from $20^{\circ} \mathrm{S}$ to $20^{\circ} \mathrm{N}$ in the tropical stratosphere. There is no significant net effect on the annual mean zonal wind in the extratropics.

Figure 8 shows the net effect of the QBO on zonal mean zonal wind during boreal winter, spring, summer and fall. It is found that in the QBO experiment, especially during the solstitial seasons, but also during the following equinoctials, the winds are more westerly in the low latitudes of the summer hemisphere, in a wide range between 70 and $2 \mathrm{hPa}$. This illustrates that mainly the weakening of the summer hemisphere easterlies causes the net westerly effect in the annual mean. The net easterly effect at $1 \mathrm{hPa}$ occurs only in the equinoctial seasons, in the westerly phase of the SAO, which is more pronounced in the noQBO experiment. Slight changes of the winter time westerly jets is noted, but the differences are not significant at the $95 \%$ level in Students t-test because of the high year-to-year variability. In northern fall, winds are a bit more westerly on both hemispheres.
Circulation differences resulting from the QBO can be illustrated effectively by discussing differences in the stream function. However, a detailed discussion of the effects is not essential for understanding of the processes involved. Hence we present the net effects of the QBO on the annual and seasonal means of stream function in Appendix 1, shown in Figs. A1a and A2a-d, and just summarize briefly the derived differences from the inclusion of the $\mathrm{QBO}$ on transport:

- Reduced upward transport in the tropical stratosphere below $60 \mathrm{hPa}$ and between 10 and $3 \mathrm{hPa}$

- Increased upward transport in the tropical middle stratosphere between 60 and $10 \mathrm{hPa}$ and in the upper stratosphere above $3 \mathrm{hPa}$

- Increased poleward transport from the tropics around $10 \mathrm{hPa}$, especially in winter and, with reduced reach, fall on each hemisphere

- Reduced poleward transport around $60 \mathrm{hPa}$, especially in winter

- Reduced poleward transport at around $4 \mathrm{hPa}$

The effects of these differences in circulation on temperature and ozone shall be discussed in the following.

The temperature QBO signal (Fig. 9b) is a direct consequence of the modulation of the Brewer-Dobson circulation. Due to the positive gradient of potential temperature with height, increased upwelling leads to cooling and decreased upwelling or subsidence produces warm anomalies. This direct connection between vertical motion and temperature also holds in the long term annual mean difference between the two experiments, as Fig. 9a illustrates. The pattern of warm-cold-warm-cold regions from $100 \mathrm{hPa}$ to $1 \mathrm{hPa}$ in the equatorial stratosphere corresponds well to the four-layer structure in the stream function. In the subtropics, the signal is reversed, as the vertical motion anomaly of the SMC is in the stream function (see Fig. A1a), but it is much weaker than in the tropics. The strongest changes occur in the tropical lower stratosphere, which is warmer by about $2 \mathrm{~K}$ in the QBO experiment, and the tropical upper stratosphere, which is colder by $1.5 \mathrm{~K}$. We also note a weak cooling of the southern polar lower stratosphere, although the QBO variation of temperature is very small in this region. On the other hand, the QBO signal in the northern polar stratosphere does not produce a net effect in the annual mean.

A more detailed picture of the QBO's net effect on temperatures is obtained from the seasonal analysis in Fig. 10a-d. The equatorial signal is similar for all seasons, except for the upper stratospheric cooling, which mostly occurs during the equinoctial seasons, a consequence of the more easterly wind shear resulting from the modified SAO due to thermal wind balance. Theses cold anomalies are accompanied by warm anomalies in the autumn hemisphere, which appear to propagate downward until winter, when they contribute to the 
relatively strong subtropical warming between 15 and $70 \mathrm{hPa}$ on the winter hemisphere. Generally, the subtropical signals are stronger on the winter hemisphere, as the $\mathrm{QBO}$ variation itself is (see, e.g. Hamilton, 1989; Bruhwiler and Hamilton, 1999; Gray, 2000).

Interestingly, temperatures are colder by about $2 \mathrm{~K}$ during fall at northern polar latitudes in the QBO model. At southern polar latitudes, the relative cooling is limited to spring (100$10 \mathrm{hPa}$ ) and summer (below $60 \mathrm{hPa}$ ), the pattern is apparently emerging from the polar vortex and propagating downwards. These polar anomalies can not be understood directly from our analysis of the mass stream function. The cold temperature in northern fall is consistent with the slightly stronger westerlies there. This supports an earlier formation of the northern vortex, which may be aided by the weaker summer easterlies. Quite likely, the difference also relates to changes in the propagation of Rossby waves (Holton and Tan, 1980; O'Sullivan and Salby, 1990; Baldwin and Gray, 2005; Calvo et al., 2007). E.g., Holton and Tan (1980) found that QBO westerly conditions in the lower stratosphere is associated with weaker wave one activity in early winter and a stronger vortex. On the other hand, the net effects in temperature can also be caused by net effects in radiatively active trace gases, which themselves originate from the change in circulation. These are the the subject of the next section.

\section{Net effects of the QBO on ozone}

In this section we apply the same analysis of QBO net effects to the ozone volume mixing ratios. Analogous effects on methane, $\mathrm{NO}_{\mathrm{x}}$ and water vapor are given in the Appendix. In short, the QBO model run has increased methane and $\mathrm{N}_{2} \mathrm{O}$ concentrations above about $10 \mathrm{hPa}$ resulting from the differences in the circulation. $\mathrm{NO}_{\mathrm{x}}$ concentrations are increased by $10-15 \%$ in the upper stratosphere, and water vapor is increased in the lower stratosphere due to increased tropopause temperature, but not so much higher up where instead methane is increased.

One might expect that the strong increase in $\mathrm{NO}_{\mathrm{x}}$ in the upper stratosphere, especially at the Equator, seriously impacts the modelled ozone concentrations, as the loss via the $\mathrm{NO}_{\mathrm{x}}$ cycle makes a major contribution to the ozone budget given in Fig. 5a. But there is no evidence for this in the QBO's net effect on ozone in our model.

Figure 11a compares the relative contributions to the ozone budget in the model runs with and without QBO. There is indeed a considerable net effect in the $\mathrm{NO}_{\mathrm{x}}$ contribution to ozone loss, it amounts to about $10 \%$ and is thus of a magnitude comparable to that of the QBO variation. It occurs at a higher altitude though, and is partly balanced by reduced losses by $\mathrm{ClO}_{\mathrm{x}}$ and $\mathrm{O}_{3}+\mathrm{O}$, and the net total loss is almost completely balanced by increased production.
Consequently, the advective contribution to the ozone budget outweighs the total chemical loss above $3 \mathrm{hPa}$, as can be seen in Fig. 11b, despite the relatively short lifetime of ozone at these levels. Only between 3 and $15 \mathrm{hPa}$ do we find the net effect on the total chemical budget to be larger than that on total transport. Below $15 \mathrm{hPa}$, the stronger upwelling in the QBO model leads to a transport loss that is partially balanced by increased total chemical production, in agreement with the findings on the total budget in Fig. $6 \mathrm{a}$.

As for the mean profile, diffusion will act to balance the remaining anomalies. Nonetheless, positive (negative) net anomalies in the total change rates of ozone coincide with net increased (reduced) mixing ratio in Fig. 12a at 12 and $50 \mathrm{hPa}(5$ and $30 \mathrm{hPa})$.

Figure 12b shows the QBO amplitude in ozone, which has a minimum at the Equator at the location of the phase reversal seen in Fig. 4. The QBO signal at midlatitudes caused by the SMC (e.g. Randel et al., 1998) is also reproduced, as well as an impact on Arctic ozone mixing ratios (e.g. O'Sullivan and Salby, 1990).

However, in the annual mean, there is no net effect of the QBO on lower- and mid-stratospheric ozone at mid-latitudes. Instead, there is a net decrease of about 3\% in the experiment with the QBO at around $5 \mathrm{hPa}$ at mid-latitudes and a slight net decrease in the southern vortex area.

Figure 13 shows the seasonal variation in the QBO's net effect on ozone. In the tropical upper stratosphere, above $3 \mathrm{hPa}$, an increase is only noted during the equinoctial seasons, when the temperature is significantly colder in the QBO model. At mid-latitudes, higher ozone volume mixing ratios are found during winter and spring in the lower stratosphere and the lower mixing ratios in the upper stratosphere are particularly pronounced during summer and fall. These patterns resemble those found for the net effect on temperature, and hence suggest that the net effects on ozone are linked to the net effects on the vertical transport.

To confirm the net effect on mid-latitude ozone, a second pair of experiments that run from 2000-2019 and only differ in the representation of the QBO was evaluated. Both experiments follow the specifications of the REF2 experiments of the CCMVal activity (Eyring et al., 2006), except for the QBO, which is included in one of the simulations only. Trace gas concentrations for these experiments are based on the IPCC A1B scenario, SSTs prescribed from a simulation of the UK Met Office HadGEM1 atmosphere-ocean GCM also assuming the A1B scenario. Halogen concentrations are based on the $\mathrm{B} 2$ scenario in the UNEP/WMO assessment of ozone depletion (WMO, 2003). The QBO is repeated from the past, chosen such that the phase agrees with observations at the beginning in January 2000. A detailed description of this procedure is given on the CCMVal website (http://www.pa.op.dlr.de/CCMVal/ Forcings/qbo_data_ccmval/u_profile_195301-200412.html). 
The net effects on zonal wind, temperature and trace gases for these experiments (not shown) agree qualitatively with the findings for the experiments 1980-1999, but those for ozone do not. Figure 14 shows the difference in stratospheric ozone volume mixing ratios found in the experiments for 2000-2019. No significant net loss is found at mid-latitudes. This result is at first surprising. It suggests that the net effect of the QBO on ozone depends on the different forcings in the future and past experiments. Specifically, the increase in CFCs during 1980-1999, which causes an increase of $\mathrm{ClO}_{\mathrm{x}}$ levels in the stratosphere and thereby affects the modelled ozone concentrations in both QBO- and noQBO experiments, levels off during 2000-2019. In contrast, the greenhouse gas emission trend is similar in both time periods, and any climatic differences due to the increased greenhouse gas levels or the different SST boundary conditions in the past and future experiments could cause differences in the net QBO effect on ozone primarily via a difference in the net effect on the circulation, which is not found in the simulations.

Hence it seems that while the net effect on mid-latitude upper stratospheric ozone is absent at constant chlorine concentrations, there is a net effect due to the positive chlorine trend in 1980-1999. The model with a QBO appears to adjust faster to the increasing CFCs, which causes the lower ozone concentrations in the 20 year mean of 1980-1999. Besides differences in the transport and chemistry of the CFCs, the effects of the volcanic eruptions of El Chichon and Mt. Pinatubo may play a role in causing this different adjustment in the two simulations, so the effect can not be attributed to the QBO alone based on our results.

\section{Conclusions}

In summary, we have forced a QBO in zonal winds based on observations in a CCM. The resulting circulation yields realistic temperature and ozone fields in the model. The QBO in ozone results from the QBO's secondary circulation in the meridional plane, with contributions from variations in (a) ozone transport with the mean flow and (b) transport of nitrogen oxides that cause ozone depletion. The combination of these two effects causes the characteristic phase shift of the ozone QBO at $13 \mathrm{hPa}$. Compared to HALOE satellite observations, the signal is slightly underestimated in the model, which is certainly related to the relatively low vertical resolution of the model in the given configuration.

Furthermore, on the long term, we found significant annual and seasonal net effects of introducing the QBO into the model on the circulation and trace gases by comparing a pair of otherwise identical CCMs. Most of the differences at mid- and low-latitudes are related to the QBO's secondary meridional circulation. E.g., reduced upwelling in the lower tropical stratosphere leads to increased temperatures at and above the tropical tropopause.
The net effects on tropical temperatures and ozone mixing ratios generally correspond to the net effects in upwelling. In the case of ozone, the net chemical production also differs for the two cases and partially cancels the transport effect in the lower stratosphere. In the upper tropical stratosphere, the QBO modulates the strength of the SAO, which, in combination with the stronger upwelling, leads to net colder temperatures and higher $\mathrm{NO}_{\mathrm{x}}$, especially in the equinoctial seasons. The higher losses via the $\mathrm{NO} / \mathrm{NO}_{2}$ cycle are however largely balanced by increased photolysis rates and reduced losses to other loss processes. The transport contribution prevails over the chemical change rate below 15 and between 1 and $3 \mathrm{hPa}$.

At mid-latitudes, we find lower ozone volume mixing ratios for the period 1980-1999 between 10 and $3 \mathrm{hPa}$ when the QBO is included in the model. A time series analysis (not shown) reveals a faster decrease of volume mixing ratios in the QBO simulation compared to the free running one. This indicates that the adjustment to the changes in the forcing, specifically the increasing CFC concentrations during 19801999, differs between the two simulations. However, it has to be kept in mind, that some of the perturbations caused by the eruptions of El Chichon and Mt. Pinatubo are only present in the model run with QBO, like the increased water vapor (see Appendix), and may have consequences relevant to ozone beyond the two year period following the eruptions that is omitted in this work. Similarly, the 11-year solar variability present in the QBO experiment affects ozone concentrations in this region and complicates the identification of the QBO's net effect. For a future study, it would be desirable to evaluate a pair of experiments with equal, constant boundary conditions except for the QBO and another pair with a linear trend in CFCs to clarify this point.

There are also significant net effects at polar latitudes in our experiments. The slight increase noted in the strength of the southern vortex when the QBO is incorporated may be due to dynamic effects related to the propagation of waves (Holton and Tan, 1982; Kinnersley and Tung, 1999). Planetary waves are barred from the tropical stratosphere during the easterly phase (e.g. Shuckburgh et al., 2001), leading to a slightly weaker BDC (Haynes et al., 1991) and a stronger, more isolated vortex. The differences in ozone and other trace gas concentrations between the two model runs can however also influence vortex dynamics. The northern vortex is slightly stronger in fall, likely for similar reasons, but not in winter and spring. Again, one could think of a further pair of experiments with no coupling of chemistry to assess the respective roles of direct and indirect effects of the changed dynamics at polar latitudes.

In this work, we focused on the period 1980-1999, for which extensive observations were available to determine to what extent the nudged QBO model produces realistic results and to elaborate the net effect of the QBO for this period.

We wish to state clearly that details of the presented net effects may be specific to the model system used here, because of its specific limitations as discussed in Eyring et al. (2006). 
Nonetheless, the overall net effects determined in this study demonstrate that the QBO affects the stratospheric circulation in multiple ways and in regions beyond those where QBO variations can be detected. There are considerable impacts on the trace gas concentrations which will feed back on the circulation via radiative heating. Accurate modelling of the stratosphere therefore requires an accurate representation of the QBO.

\section{Appendix A}

\section{Net effect in stream function and further trace gases}

The method to calculate the net effect of the QBO as described in the text was applied to additional quantities besides zonal wind, temperature and ozone. As for the latter, the QBO amplitude and the seasonal net differences were also computed. The results are given in Figs. A1 and A2.

The mass stream function was chosen because it best illustrates the net effect of the QBO on the meridional circulation. In Fig. A1a, the contours give the stream function for the QBO experiments. In the stratosphere there are two large circulation cells of opposite sign on the two hemispheres that describe the Brewer-Dobson circulation. Contour lines give the direction of the flow, which is clockwise for positive stream function and anti-clockwise for negative stream function, and the density of isolines gives the strength of the flow.

The net effect of the QBO as shown in the shades of Fig. A1a is largely antisymmetric with respect to the Equator. In the lower stratosphere, upwelling is weaker in the simulation with a QBO which affects the time scale of the tape recorder signal in water vapor (Giorgetta et al., 2006). Higher up, at around $30 \mathrm{hPa}$, the effect is reversed and the circulation is stronger by up to 5\% in the QBO experiment. There are two further alternating pairs of cells in the upper stratosphere, located at 7 and $2 \mathrm{hPa}$. The panels a-d of Fig. A2 show the large seasonal variations of the stream function.

In addition to ozone, we give the QBO effects and amplitudes for three further prominent trace gases in the stratosphere. Methane, water vapor and nitrogen oxides $\left(\mathrm{NO}_{\mathrm{x}}=\mathrm{NO}+\mathrm{NO}_{2}+\mathrm{NO}_{3}+0.5 \mathrm{~N}_{2} \mathrm{O}_{5}\right)$ were selected for their roles in the radiation budget and the chemistry of ozone.

The net effect of the QBO on methane, shown in Fig. A1c, is a substantial increase in the mole fraction over a wide range of the stratosphere above $40 \mathrm{hPa}$. The absolute net effect is largest in the tropics between 10 and $5 \mathrm{hPa}$, which can be attributed to the increased upwelling in the middle stratosphere. At mid-latitudes, the net difference between the methane concentrations in the QBO and noQBO experiments is strongest at around $10 \mathrm{hPa}$. It can be explained by the higher poleward transport at these levels indicated by the differences between the stream functions in the two experi- ments. Figure A1d shows the amplitude of the QBO variations in methane in the nudged model experiment. The dark contours show that the amplitude is of the order of $5-10 \%$ of the mean volume mixing ratio in a large part of the extratropical stratosphere.

Figure A2e-h confirm that the increased methane volume mixing ratios occur mainly in winter and spring on both hemispheres, as can be expected from the analysis of the mass stream function. There is a slight reduction of the methane mole fraction between $20^{\circ}$ and $30^{\circ} \mathrm{N}$ at around $30 \mathrm{hPa}$ during summer and spring, especially on the Southern Hemisphere.

The stratospheric concentrations of water vapor are elevated up to 6 years after the big volcanic eruptions in the model run with QBO, while they are not in the noQBO run. To eliminate the resulting net difference in the 20-year means between the two experiments, six years after the eruptions of El Chichon and Mt. Pinatubo were excluded for the analyses of the water vapor field, in contrast to the other quantities. Unfortunately, this leaves only 8 years or about three QBO cycles and hence reduces the reliability of the results. Fig. A1e shows that nonetheless a QBO signal in tropical water vapor is retained. It occurs at $10 \mathrm{hPa}$, thus at a lower altitude than in satellite observations (Randel et al., 1998, 2004; Schoeberl et al., 2008), as mentioned in Sect. 2. In the model, the signal is about half as strong as analysed in the HALOE record by Schoeberl et al. (2008).

The net effect of the QBO, given in Fig. A1e, is clearly dominated by the tropopause temperature effect. There is a surplus of up to $10 \%$ above the tropical tropopause and around 5\% in most of the lower stratosphere in the model simulation with nudged QBO compared to the free running model.

The seasonal analysis in the Panels i-1 of Figure A2 confirms that most of the net effect in the lower stratosphere seen in Fig. A1e is due to the QBO's net effect on tropopause temperatures. A comparison to Fig. A2e-h reveals that in the middle and upper stratosphere, regions with higher water vapor in the QBO run coincide with the regions where methane mole fraction is not elevated with respect to the noQBO run, hence the net effect on total hydrogen is about constant in the entire stratosphere.

At the Equator, volume mixing ratios of $\mathrm{NO}_{\mathrm{x}}$ are maximum at around $5 \mathrm{hPa}$. Fig. A1h shows that there is a $\mathrm{QBO}$ signal in $\mathrm{NO}_{\mathrm{x}}$ in two regions above and below the maximum. It thus seems that the $\mathrm{QBO}$ in $\mathrm{NO}_{\mathrm{x}}$ is caused by the $\mathrm{QBO}$ in upwelling and the tracer gradient. As discussed in the text, this signal makes an important contribution to the QBO in ozone.

The net effect in $\mathrm{NO}_{\mathrm{x}}$ is shown in Fig. A1g. In the QBO simulation, there is slightly less $\mathrm{NO}_{\mathrm{x}}$ in the tropics between 15 and $30 \mathrm{hPa}$ than in the QBO less reference simulation. The net downwelling between 5 and $10 \mathrm{hPa}$ and net upwelling above are consistent with elevated $\mathrm{NO}_{\mathrm{x}}$ below and above the maximum. However, we assume that most of the net 

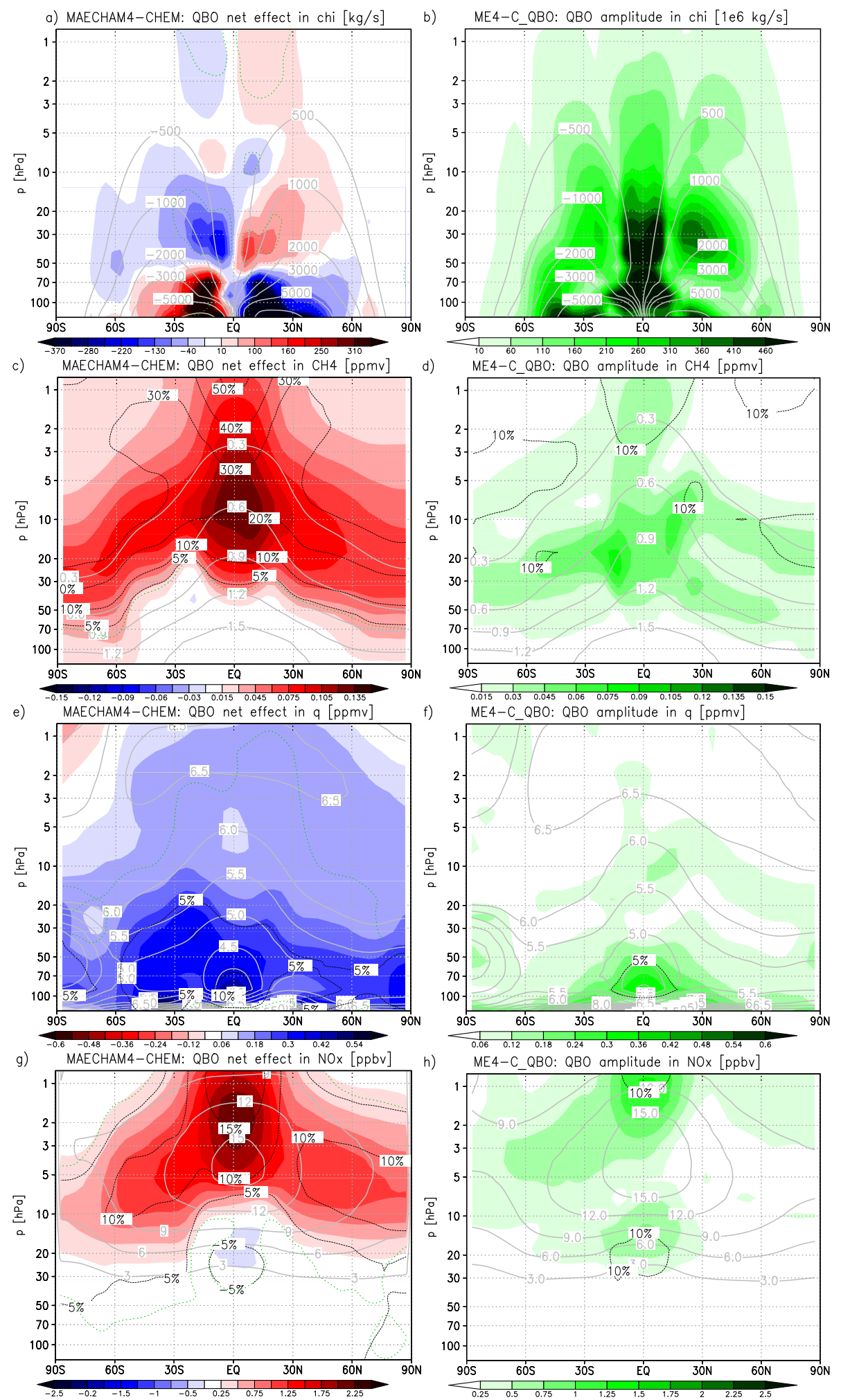

Fig. A1. As Fig. 7, but for mass stream function $\left[10^{6} \mathrm{~kg} / \mathrm{s}\right](\mathbf{a}-\mathbf{b})$, and the volume mixing ratios of methane $[\mathrm{ppmv}](\mathbf{c}-\mathbf{d})$, water vapor [ppmv] (e-f) and nitrogen oxides [ppbv] (g-h). 

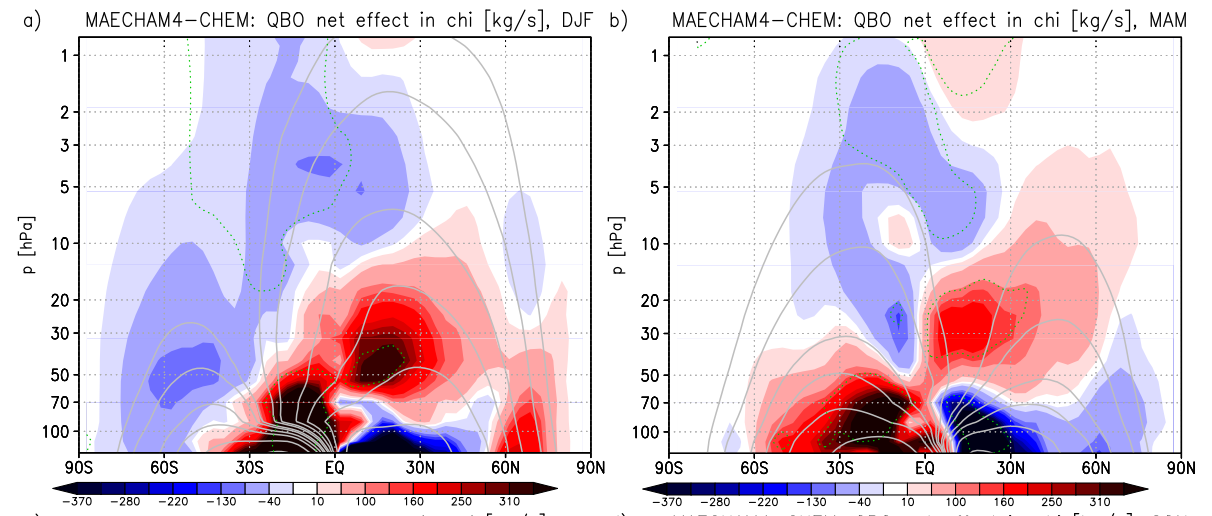

c) MAECHAM4-CHEM: QBO net effect in chi $[\mathrm{kg} / \mathrm{s}]$, JJA d)
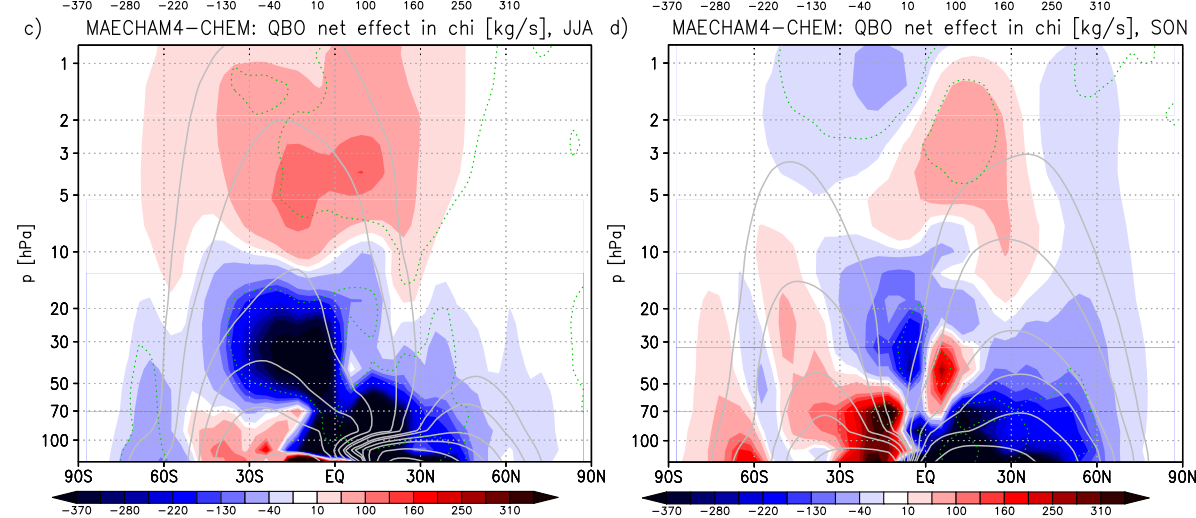

e) MAECHAM4-CHEM: QBO net effect in $\mathrm{CH} 4$ [ppmv], DJF f)
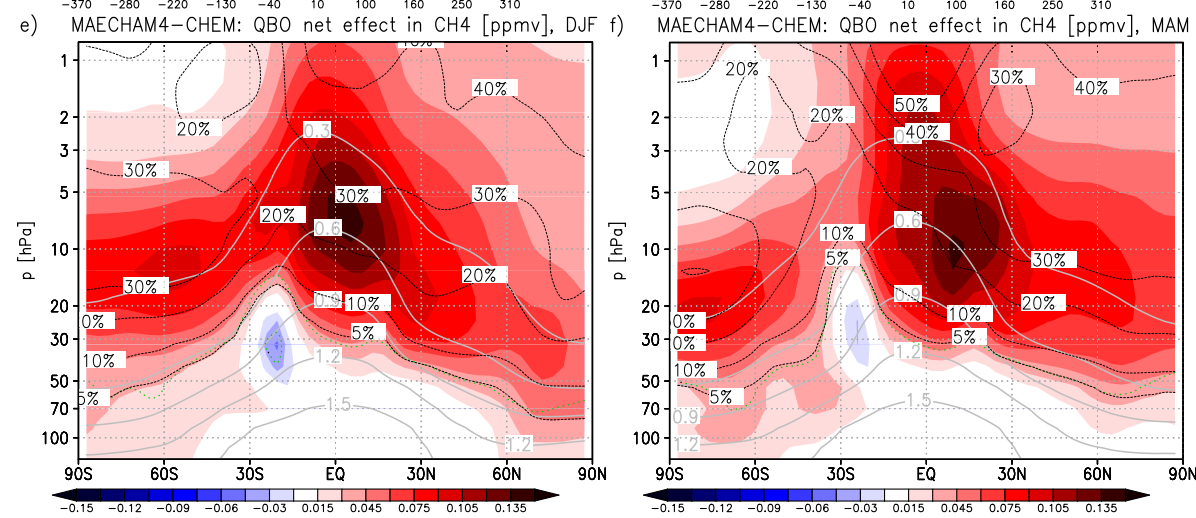

g) MAECHAM4-CHEM: QBO net effect in $\mathrm{CH} 4$ [ppmv], JJA h) MAECHAM4-CHEM: QBO net effect in CH4 [ppmv], SON
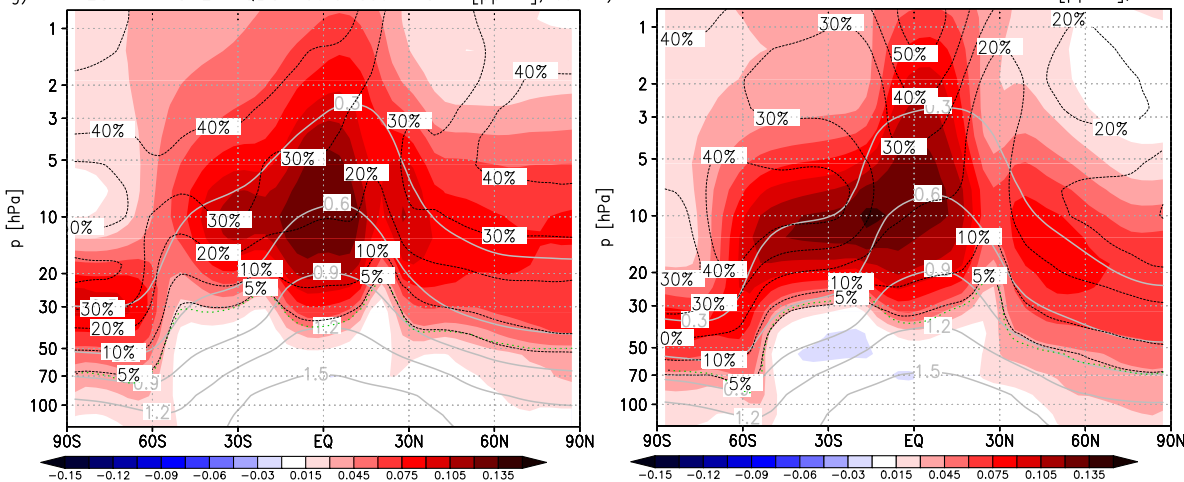

Fig. A2. As Fig. 8, but for mass stream function $\left[10^{6} \mathrm{~kg} / \mathrm{s}\right](\mathbf{a}-\mathbf{d})$, and the volume mixing ratios of methane [ppmv] (e-h), water vapor [ppmv] (i-l) and nitrogen oxides [ppbv] (m-p). 

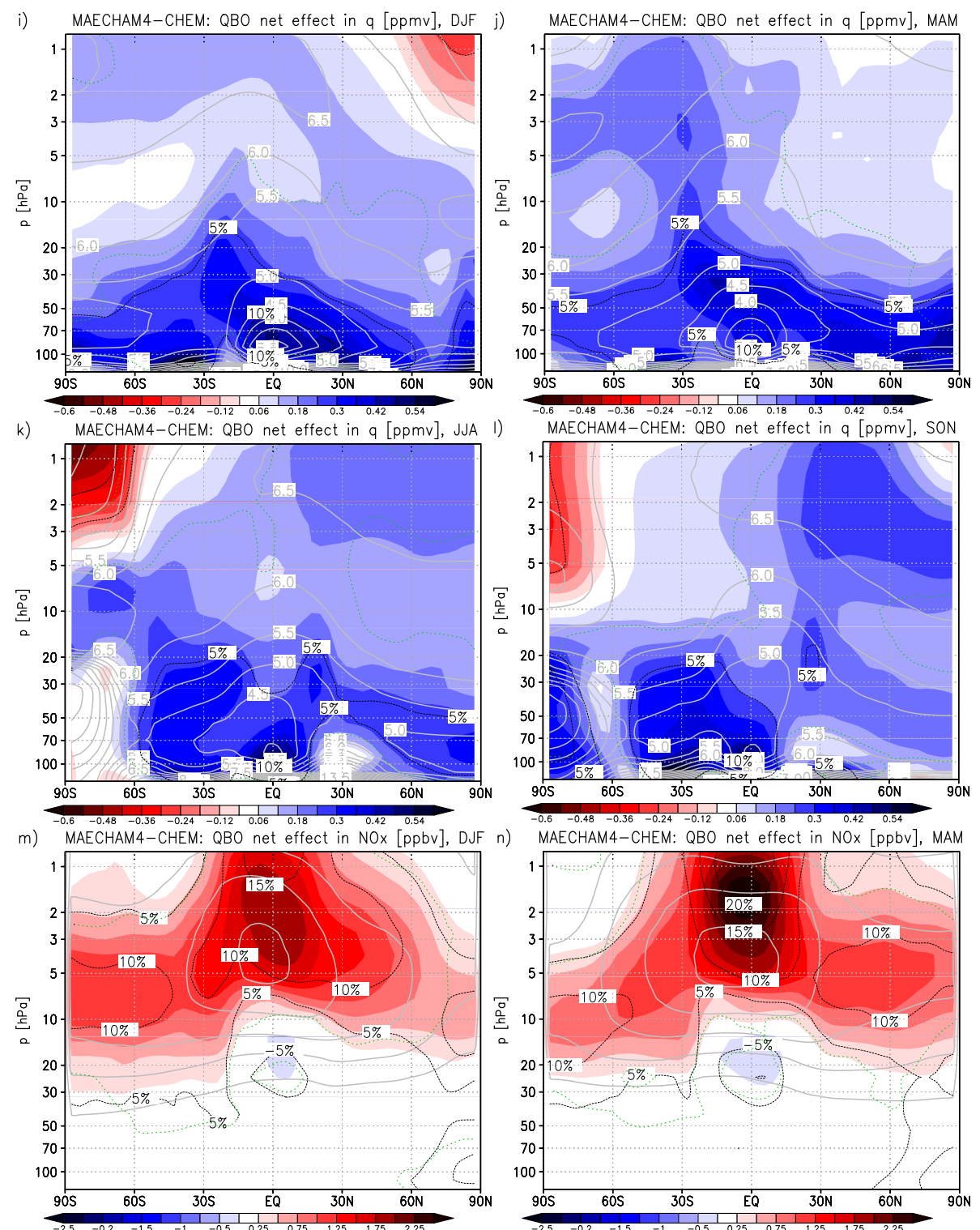

o) MAECHAM4-CHEM: QBO net effect in NOx [ppbv], JJA P)
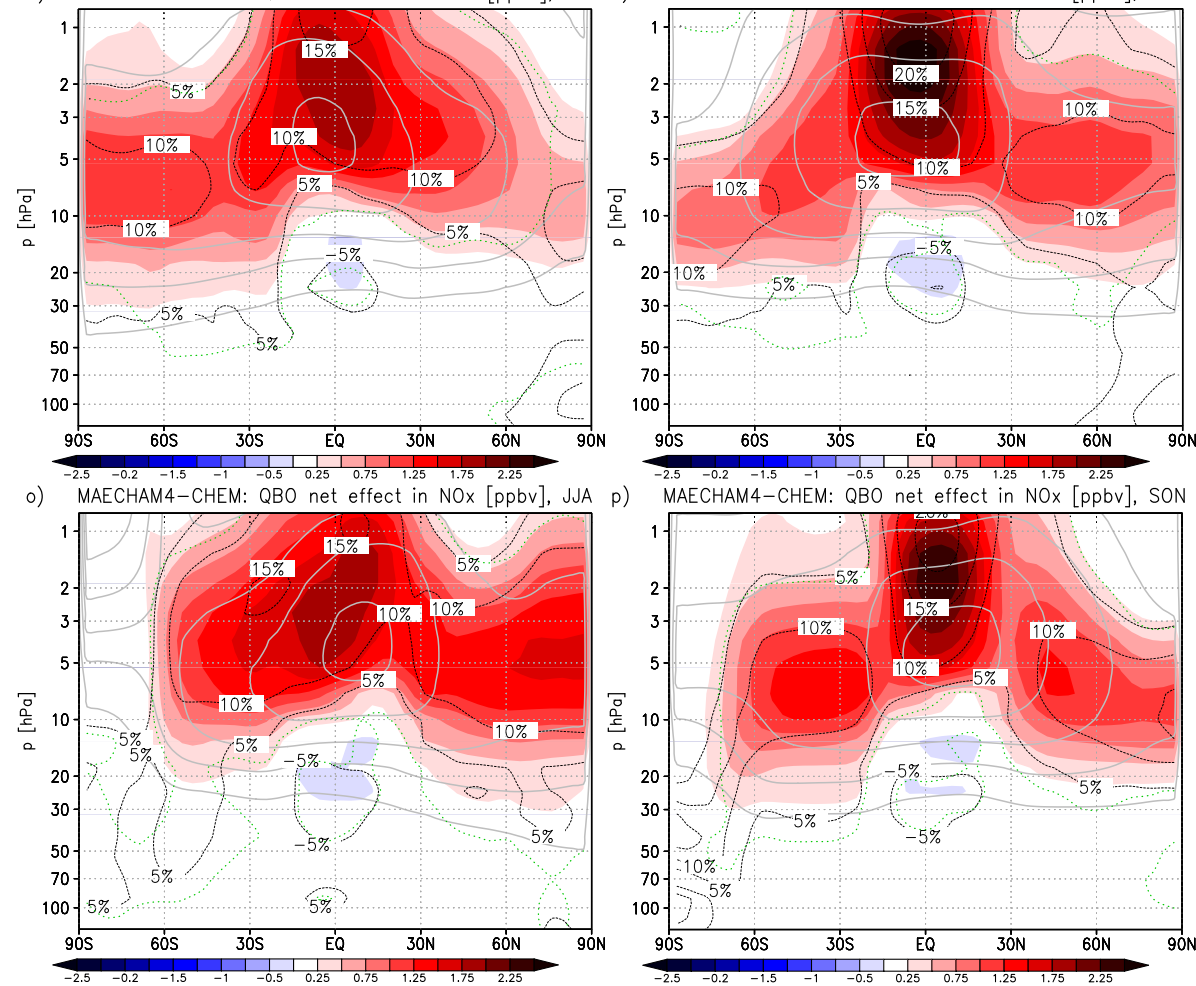

Fig. A2. Continued. 
effect comes from increased production of $\mathrm{NO}_{\mathrm{x}}$ from $\mathrm{N}_{2} \mathrm{O}$, for which the pattern of the net effect (not shown) is very similar to that in methane.

The panels $\mathrm{m}-\mathrm{p}$ of Fig. A2 show the net effect in $\mathrm{NO}_{\mathrm{x}}$ for the four seasons. The net gain in $\mathrm{NO}_{\mathrm{x}}$ in the upper stratosphere is strongest during the equinoctial seasons. There is some connection to the temperature signal, as net easterly shear in the region in the equinoctial seasons leads to (1) cooling due to thermal wind balance and (2) a net meridional circulation, that in this case causes enhanced upwelling of $\mathrm{NO}_{\mathrm{x}}$ rich air from below. Hence we find the coincidence of cold temperatures and high $\mathrm{NO}_{\mathrm{x}}$ concentrations. On the other hand, a larger part of the excess $\mathrm{NO}_{\mathrm{x}}$ will be advected towards the winter hemisphere during the solstitial seasons. An increase of $\mathrm{NO}_{\mathrm{x}}$ volume mixing ratios at mid-latitudes by $10-15 \%$ above $20 \mathrm{hPa}$ is however found during all seasons in the $\mathrm{QBO}$ versus the noQBO experiment.

Acknowledgements. The authors gratefully acknowledge ECMWF for providing the ERA-40 reanalysis data and the UARS-HALOE team for the ozone data. The authors thank Sebastian Rast and Hauke Schmidt for valuable comments during the preparation of this work, and the reviewers for their comments that led to various clarifications. This work was supported by the European Commission and the EC Integrated Project SCOUT-O3 (505390GOCE-CT-2004).

Edited by: K. Hamilton

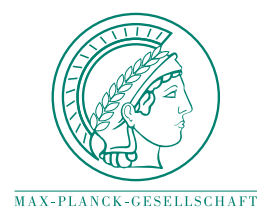

This Open Access Publication is financed by the Max Planck Society.

\section{References}

Akmaev, R. A., Fomichev, V. I., and Zhu, X.: Impact of middleatmospheric composition changes on greenhouse cooling in the upper atmosphere, J. Atmos. Sol.-Terr. Phys., 68, 17, 1879-1889, doi:10.1016/j.jastp.2006.03.008, 2006.

Austin, J.: A Three-Dimensional Coupled Chemistry-Climate Model Simulation of Past Stratospheric Trends, J. Atmos. Sci., 59, 218-232, doi:10.1175/1520-0469(2002)059/0218: ATDCCC) 2.0.CO;2, 2002.

Baldwin, M. P. and Gray, L. J.: Tropical stratosphere zonal winds in ECMWF ERA-40 reanalysis, rocketsonde data, and rawinsonde data, Geophys. Res. Lett., 32, L09806, doi:10.1029/ 2004GL022328, 2005.

Baldwin, M. P., Gray, L. J., Dunkerton, T. J., Hamilton, K., Haynes, P. H., Randel, W. J., Holton, J. R., Alexander, M. J., Hirota, I., Horinouchi, T., Jones, D. B. A., Kinnersley, J. S., Marquardt, C., Sato, K., and Takahashi, M.: The Quasi-Biennial Oscillation, Rev. Geophys., 39, 179-229, 2001.

Brasseur, G. P., Orlando, J. J., and Tyndall, G. S.: Atmospheric Chemistry and Global Change, Oxford University Press, New York, NY, USA, 1999.
Bruhwiler, L. P. and Hamilton, K.: A numerical simulation of the stratospheric ozone quasi-biennial oscillation using a comprehensive general circulation model, J. Geophys. Res., 104, 30 525-30 557, 1999.

Butchart, N., Scaife, A. A., Austin, J., Hare, S. H. E., and Knight, J. R.: Quasi-biennial oscillation in ozone in a coupled chemistryclimate model, J. Geophys. Res., 108, 4486, 2003.

Calvo, N., Giorgetta, M. A., and Pena-Ortiz, C.: Sensitivity of the boreal winter circulation in the middle atmosphere to the quasibiennial oscillation in MAECHAM5 simulations, J. Geophys. Res., 112, D10124, doi:10.1029/2006JD007844, 2007.

Chipperfield, M. P. and Gray, L. J.: Two-Dimensional Model Studies of the Interannual Variability of Trace Gases in the Middle Atmosphere, J. Geophys. Res., 97, 5963-5980, 1992.

Chipperfield, M. P., Gray, L. J., Kinnersley, J. S., and Zawodny, J.: A two-dimensional model study of the QBO signal in SAGE II $\mathrm{NO}_{2}$ and $\mathrm{O}_{3}$, Geophys. Res. Lett., 21, 589-592, 1994.

Cordero, E. C., Kawa, S. R., and Schoeberl, M. R.: An analysis of tropical transport: Influence of the quasi-biennial oscillation, J. Geophys. Res., 102, 16453-16462, doi:10.1029/97JD01053, 1997.

Dunkerton, T. J.: Quasi-Biennal and subbiennal Variations of Stratospheric Trace Constituents Derived from HALOE Observations, J. Atmos. Sci., 58, 7-25, 2001.

Eyring, V., Butchart, N., Waugh, D. W., Akiyoshi, H., Austin, J., Bekki, S., Bodeker, G. E., Boville, B. A., Brühl, C., Chipperfield, M. P., Cordero, E., Dameris, M., Deushi, M., Fioletov, V. E., Frith, S. M., Garcia, R. R., Gettelman, A., Giorgetta, M. A., Grewe, V., Jourdain, L., Kinnison, D. E., Mancini, E., Manzini, E., Marchand, M., Marsh, D. R., Nagashima, T., Newman, P. A., Nielsen, J. E., Pawson, S., Pitari, G., Plummer, D. A., Rozanov, E., Schraner, M., Shepherd, T. G., Shibata, K., Stolarski, R. S., Struthers, H., Tian, W., and Yoshiki, M.: Assessment of temperature, trace species and ozone in chemistry-climate model simulations of the recent past, J. Geophys. Res., 111, D22308, doi: 10.1029/2006JD007327, 2006.

Giorgetta, M. A. and Bengtsson, L.: Potential role of the quasibiennial oscillation in stratosphere-troposphere exchange as found in water vapor in general circulation model experiments, J. Geophys. Res., 104, 6003-6020, 1999.

Giorgetta, M. A., Manzini, E., Roeckner, E., Esch, M., and Bengtsson, L.: Climatology and Forcing of the Quasi-Biennial Oscillation in the MAECHAM5 Model, J. Climate, 19, 3882-3901, 2006.

Gray, L. J.: A model study of the influence of the quasi-biennial oscillation on trace gas distributions in the middle and upper stratosphere, J. Geophys. Res., 105, 4539-4552, doi:10.1029/ 1999JD900320, 2000.

Hamilton, K.: Interhemispheric asymmetry and annual synchronization of the ozone quasi-biennial oscillation, J. Atmos. Sci., 46, 1019-1025, 1989.

Hamilton, K. and Hsieh, W. W.: Representation of the quasibiennial oscillation in the tropical stratospheric wind by nonlinear principal component analysis, J. Geophys. Res., 107(D15), 4232, doi:10.1029/2001JD001250, 2002.

Hasebe, F.: Quasi-Biennial Oscillations of Ozone and Diabatic Circulation in the Equatorial Stratosphere, J. Atmos. Sci., 51, 729745, 1994.

Haynes, P. H., McIntyre, M. E., Shepherd, T. G., Marks, C. J., and 
Shine, K. P.: On the "Downward Control" of Extratropical Diabatic Circulations by Eddy-Induced Mean Zonal Forces., J. Atmos. Sci., 48, 651-680, 1991.

Holton, J. R. and Tan, H.-C.: The influence of the equatorial quasibiennial oscillation on the global circulation at $50 \mathrm{mb}$, J. Atmos. Sci., 37, 2200-2208, 1980.

Holton, J. R. and Tan, H.-C.: The quasi-biennial oscillation in the Northern Hemisphere lower stratosphere, J. Meteorol. Soc. Jpn., 60, 140-148, 1982.

Huesmann, A. S. and Hitchman, M. H.: The stratospheric quasibiennial oscillation in the NCEP reanalyses: Climatological structures, J. Geophys. Res., 106, 11 859-11 874, 2001.

Jackman, C. H., Fleming, E. L., Chandra, S., Considine, D. B., and Rosenfield, J. E.: Past, present, and future modeled ozone trends with comparisons to observed trends, J. Geophys. Res., 101, 28 753-28 768, doi:10.1029/96JD03088,, 1996.

Kinnersley, J. S. and Tung, K.: Mechanisms for the Extratropical QBO in Circulation and Ozone, J. Atmos. Sci., 56, 1942-1962, 1999.

Kirchner, I., Stenchikov, G. L., Graf, H.-F., Robock, A., and Antuña, J. C.: Climate model simulation of winter warming and summer cooling following the 1991 Mount Pinatubo volcanic eruption, J. Geophys. Res., 104, 19 039-19 056, doi:10.1029/ 1999JD900213, 1999.

Lean, J. L., Rottman, G. J., Kyle, H. L., Woods, T. N., Hickey, J. R., and Puga, L. C.: Detection and parameterization of variations in solar mid- and near-ultraviolet radiation (200-400 nm)., J. Geophys. Res., 102, 29 939-29956, 1997.

Lelieveld, J., Brühl, C., Jöckel, P., Steil, B., Crutzen, P. J., Fischer, H., Giorgetta, M. A., Hoor, P., Lawrence, M. G., Sausen, R., and Tost, H.: Stratospheric dryness: model simulations and satellite observations, Atmos. Chem. Phys., 7, 1313-1332, 2007, http://www.atmos-chem-phys.net/7/1313/2007/.

Logan, J. A., Jones, D. B. A., Megretskaia, I. A., Oltmans, S. J., Johnson, B. J., Vömel, H., Randel, W. J., Kimani, W., and Schmidlin, F. J.: Quasibiennial oscillation in tropical ozone as revealed by ozonesonde and satellite data, J. Geophys. Res., 108(D8), 4244, doi:10.1029/2002JD002170, 2003.

Manzini, E. and McFarlane, N. A.: The effect of varying the source spectrum of a gravity wave parameterization in a middle atmosphere general circulation model, J. Geophys. Res., 103, 31 523$31539,1998$.

Manzini, E., Steil, B., Brühl, C., Giorgetta, M. A., and Krüger, K.: A new interactive chemistry-climate model: Sensitivity of the middle atmosphere to ozone depletion and increase in greenhouse gases and implications for recent stratospheric cooling, J. Geophys. Res., 108, 4429, doi:10.1029/2002JD002977, 2003.

Naujokat, B.: An Update of the Observed Quasi-Biennial Oscillation of the Stratospheric Winds over the Tropics, J. Atmos. Sci., 43, 17, 1873-1880, 1986.

O'Sullivan, D. and Dunkerton, T. J.: The influence of the quasibiennial oscillation on global constituent distributions, J. Geophys. Res., 102, 21 731-21 744, 1997.

O'Sullivan, D. and Salby, M. L.: Coupling of the Quasi-biennial Oscillation and the Extratropical Circulation in the Stratosphere through Planetary Wave Transport, J. Atmos. Sci., 47, 650-673, 1990.

Patra, P. K., Lal, S., Venkataramani, S., and Chand, D.: Halogen Occultation Experiment (HALOE) and balloon-borne in situ mea- surements of methane in stratosphere and their relation to the quasi-biennial oscillation (QBO), Atmos. Chem. Phys., 3, 10511062, 2003,

http://www.atmos-chem-phys.net/3/1051/2003/.

Plumb, R. A. and Bell, R. C.: A model of the quasi-biennial oscillation on an equatorial beta-plane, Q. J. R. Meteorol. Soc., 108, 335-352, 1982.

Punge, H. J. and Giorgetta, M. A.: Differences between the QBO in the first and in the second half of the ERA-40 reanalysis, Atmos. Chem. Phys., 7, 599-608, 2007,

http://www.atmos-chem-phys.net/7/599/2007/.

Randel, W. J. and Wu, F.: Isolation of the Ozone QBO in SAGE II Data by Singular-Value Decomposition, J. Atmos. Sci., 53, 2546-2559, doi:10.1175/1520-0469(1996)053〈2546:IOTOQI $\rangle$. $0 . \mathrm{CO} ; 2,1998$.

Randel, W. J., Wu, F., Russel, J. W., Roche, A., and Waters, J.: Seasonal cycles and QBO variations in stratospheric $\mathrm{CH} 4$ and H2O observed in UARS HALOE data, J. Atmos. Sci., 55, 163185, 1998.

Randel, W. J., Wu, F., Oltmans, S. J., K.Rosenlof, and Nedoluha, G. E.: Interannual changes of stratospheric water vapor and correlations with tropical tropopause temperatures, J. Atmos. Sci., 61, 2133-2147, 2004.

Rayner, N. A., Parker, D. E., Horton, E. B., Folland, C. K., Alexander, L. V., Rowell, D. P., Kent, E. C., and Kaplan, A.: Global analyses of sea surface temperature, sea ice, and night marine air temperature since the late nineteenth century, J. Geophys. Res., 108, 4407, doi:10.1029/2002JD002670, 2003.

Roeckner, E., Arpe, K., Bengtsson, L., Christoph, M., Claussen, M., Dümenil, L., Esch, M., Giorgetta, M. A., Schlese, U., and Schulzweida, U.: The atmospheric general circulation model ECHAM4: Model description and simulation of present-day climate, Max Planck Institut für Meteorologie - Report No. 218, Hamburg, 1996.

Schmidt, H., Brasseur, G. P., Charron, M., Manzini, E., Giorgetta, M. A., Diehl, T., Fomichev, V. I., Kinnison, D., Marsh, D., and Walters, S.: The HAMMONIA chemistry climate model: Sensitivity of the mesopause region to the 11-year solar cycle and $\mathrm{CO}_{2}$ doubling, J. Clim., 19, 3903-3931, 2006.

Schoeberl, M. R., Douglass, A. R., Newman, P. A., Lait, L. R., Lary, D., Waters, J., Livesey, N., Froidevaux, L., Lambert, A., Read, W., Filipiak, M. J., and Pumphrey, H. C.: QBO and Annual Cycle Variations in Tropical Lower Stratosphere Trace Gases from HALOE and Aura MLS Observations, J. Geophys. Res., 113, D05301, doi:10.1029/2007JD008678, 2008.

Shibata, K. and Deushi, M.: Partitioning between resolved wave forcing and unresolved gravity wave forcing to the quasi-biennial oscillation as revealed with a coupled chemistry-climate model, Geophys. Res. Lett., 32, L12820, doi:10.1029/2005GL022885, 2005.

Shuckburgh, E., Norton, W., Iwi, A., and Haynes, P.: Influence of the quasi-biennial oscillation on isentropic transport and mixing in the tropics and subtropics, J. Geophys. Res., 106, $14327-$ 14338, 2001.

Steil, B., Dameris, M., Brüh1, C., Crutzen, P. J., Grewe, V., Ponater, M., and Sausen, R.: Development of a chemistry module for GCMs: first results of a multiannual integration, Ann. Geophys., 16, 205-228, 1998, http://www.ann-geophys.net/16/205/1998/. 
Steil, B., Brühl, C., Manzini, E., Crutzen, P. J., Lelieveld, J., Rasch, P. J., Roeckner, E., and Krüger, K.: A new interactive chemistryclimate model: 1. Present-day climatology and interannual variability of the middle atmosphere using the model and 9 years of HALOE/UARS data, J. Geophys. Res., 108(D9), 4290, doi: 10.1029/2002JD002971, 2003.

Steinbrecht, W., Haßler, B., Brühl, C., Dameris, M., Giorgetta, M. A., Grewe, V., Manzini, E., Matthes, S., Schnadt, C., Steil, B., and Winkler, P.: Interannual variation patterns of total ozone and lower stratospheric temperature in observations and model simulations, Atmos. Chem. Phys., 6, 349-374, 2006, http://www.atmos-chem-phys.net/6/349/2006/.

Takahashi, M.: Simulation of the stratospheric quasi-biennial oscillation using a general circulation model, Geophys. Res. Lett., 23, 661-664, 1996.

Tian, W. S. and Chipperfield, M. P.: A new coupled chemistryclimate model for the stratosphere: The importance of coupling for future $\mathrm{O}_{3}$-climate predictions, Q. J. R. Meteorol. Soc., 131, 281-303, 2005.

Tian, W., Chipperfield, M. P., Gray, L. J., and Zawodny, J. M.: Quasi-biennial oscillation and tracer distributions in a coupled chemistry-climate model, J. Geophys. Res., 111, D20301, doi: 10.1029/2006JD006871, 2006.

Tourpali, K., Schuurmans, C. J. E., van Dorland, R., Steil, B., and Brühl, C.: Stratospheric and tropospheric response to enhanced solar UV radiation: A model study, Geophys. Res. Lett., 30(5), 1231, doi:10.1029/2002GL016650, 2003.
Trepte, C. R. and Hitchman, M. H.: Tropical stratospheric circulation deduced from satellite aerosol data, Nature, 355, 626-628, doi:10.1038/355626a0, 1992.

Uppala, S., Kallberg, P., Hernandez, A., Saarinen, S., Fiorino, M., Li, X., Onogi, K., Sokka, N., Andrae, U., and Bechtold, V. D. C.: ERA-40: ECMWF 45-year reanalysis of the global atmosphere and surface conditions 1957-2002, ECMWF Newsletter, 101, 2-21, 2004.

Witte, J. C., Schoeberl, M. R., Douglass, A. R., and Thompson, A. M.: The Quasi-biennial Oscillation and annual variations in tropical ozone from SHADOZ and HALOE, Atmos. Chem. Phys., 8, 3929-3936, online available at: http://www. atmos-chem-phys.net/8/3929/2008/, 2008.

WMO: Scientific Assessment of Ozone Depletion: 2003, Global Ozone Research and Monitoring Project - Report No. 47, Geneva, 2003.

Zawodny, J. M. and McCormick, M. P.: Stratospheric Aerosol and Gas Experiment II measurements of the quasi-biennial oscillations in ozone and nitrogen dioxide, J. Geophys. Res., 96, 93719377, 1991. 